Marquette University

e-Publications@Marquette

8-4-2016

First Experimental Evidence for the Diverse Requirements of Excimer vs Hole Stabilization in $\pi$ Stacked Assemblies

Neil Reilly

Marquette University

Maxim Vadimovich Ivanov

Marquette University

Brandon Uhler

Marquette University

Marat R. Talipov

Marquette University

Rajendra Rathore

Marquette University

See next page for additional authors

Accepted version. Journal of Physical Chemistry Letters, Vol. 7, No. 15 (August 4, 2016): 3042-3045.

DOI. (C) 2016 American Chemical Society. Used with permission. 
Authors

Neil Reilly, Maxim Vadimovich Ivanov, Brandon Uhler, Marat R. Talipov, Rajendra Rathore, and Scott Reid 


\title{
First Experimental Evidence for the Diverse Requirements of Excimer vs Hole Stabilization in $\pi$-Stacked Assemblies
}

\author{
Neil Reilly \\ Department of Chemistry, Marquette University, \\ Milwaukee, WI \\ Maxim Ivanov \\ Department of Chemistry, Marquette University, \\ Milwaukee, WI \\ Brandon Uhler \\ Department of Chemistry, Marquette University, \\ Milwaukee, WI \\ Marat Talipov \\ Department of Chemistry, Marquette University, \\ Milwaukee, WI \\ Rajendra Rathore \\ Department of Chemistry, Marquette University, \\ Milwaukee, WI
}

Journal of Physical Chemistry Letters, Vol 7, No. 15 (August 4, 2016): pg. 3042-3045. DOI. This article is (C) American Chemical Society and permission has been granted for this version to appear in e-Publications@Marquette. American Chemical Society does not grant permission for this article to be further copied/distributed or hosted elsewhere without the express permission from American Chemical Society. 
NOT THE PUBLISHED VERSION; this is the author's final, peer-reviewed manuscript. The published version may be accessed by following the link in the citation at the bottom of the page.

\section{Scott A. Reid \\ Department of Chemistry, Marquette University, Milwaukee, WI}

\section{Abstract}

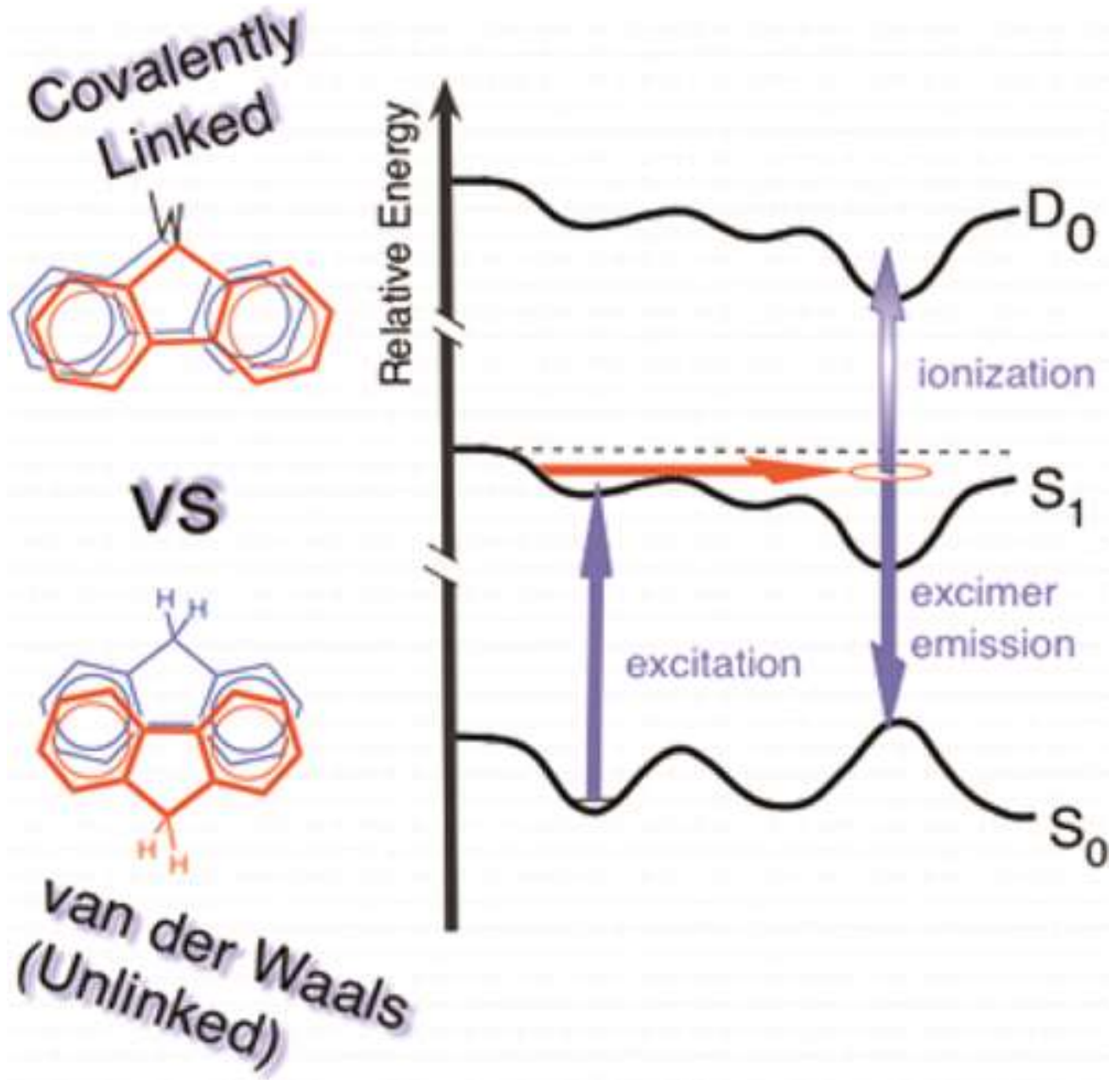

Exciton formation and charge separation and transport are key dynamical events in a variety of functional polymeric materials and biological systems, including DNA. Beyond the necessary cofacial approach of a pair of aromatic molecules at van der Waals contact, the extent of overlap and necessary geometrical reorganization for optimal stabilization of an excimer vs dimer cation radical remain unresolved. Here, we compare experimentally the

Journal of Physical Chemistry Letters, Vol 7, No. 15 (August 4, 2016): pg. 3042-3045. DOI. This article is (C) American Chemical Society and permission has been granted for this version to appear in e-Publications@Marquette. American Chemical Society does not grant permission for this article to be further copied/distributed or hosted elsewhere without the express permission from American Chemical Society. 
NOT THE PUBLISHED VERSION; this is the author's final, peer-reviewed manuscript. The published version may be accessed by following the link in the citation at the bottom of the page.

dynamics of excimer formation (via emission) and charge stabilization (via threshold ionization) of a novel covalently linked, cofacially stacked fluorene dimer (F2) with the unlinked van der Waals dimer of fluorene, that is, $(F)_{2}$. Although the measured ionization potentials are identical, the excimeric state is stabilized by up to $\sim 30 \mathrm{~kJ} / \mathrm{mol}$ in covalently linked F2. Supported by theory, this work demonstrates for the first time experimentally that optimal stabilization of an excimer requires a perfect sandwich-like geometry with maximal overlap, whereas hole stabilization in $n$-stacked aggregates is less geometrically restrictive.

The dynamics of exciton and hole formation and migration in $\Pi$ stacked assemblies are central to the mechanisms of biological systems and the development of functional polymeric materials. 1 As the simplest units capable of excimer formation and charge delocalization, dimers of benzene, $, 2,3$ fluorene, $, 4,5$ naphthalene, $\underline{6}$ and pyrene $\underline{Z}$ have served as models for understanding excitonic interactions and electron transfer in multichromophoric assemblies. $\frac{8-10}{}$ Though it is appreciated that $n$-stacked assemblies stabilize both charge and excitation energy, the geometrical reorganizations and underlying mechanisms accompanying these important events are not well understood nor, indeed, is there a unified understanding of $n-$ stacking interactions. $\underline{11,12}$

Representing a significant advance in our ability to study $\Pi-$ stacked aggregates, the Rathore group reported the synthesis and spectroscopic characterization of a novel set of polyfluorenes covalently linked at the 9-position through a single methylene spacer (denoted Fn; $n=1-6) .13-17$ These molecules adopt a cofacial arrangement in gas, liquid, and solid state and have been utilized as model systems to examine energy and electron transport in $\Pi$-stacked assemblies. $\frac{18}{}$ Herein, we use F2 as a model covalently linked system, which we compare with the unlinked (i.e., van der Waals) dimer of fluorene, that is, $(F)_{2}$ in order to examine the geometrical requirements for excimer vs dimer cation radical stabilization. Utilizing a powerful experimental approach in vacuo which monitors emission or delayed ionization from the excimeric states, we compare emission and resonant ionization spectra of the two dimers, which affords a facile comparison of the relative stabilization of excimer vs hole (i.e., cation radical). We thus probe for the first time the relative efficiency and geometrical requirements of excimer formation vs charge stabilization in a model bichromophore. 
A schematic of the experiment is shown in Figure 1. Our studies were carried out on isolated cold ( $T_{\text {rot }} \sim 20 \mathrm{~K}$ ) molecules in the gasphase using a supersonic nozzle; details are provided in the Supporting Information (SI). In each case, laser excitation from the ground state minimum placed the dimer on the $S_{1}$ surface, where rapid rearrangement resulted in excimer formation, evidenced in the dominance of excimer emission and a lengthened fluorescence lifetime. Analysis of line widths in the (F) 2 spectrum (Figure $\mathrm{S} 1$ ) indicate a time scale for this process of several picoseconds, consistent with recent studies of the benzene dimer. $\underline{19}$ From the excimeric well, absorption of a photon from a second laser pulse, delayed by $\sim 5 \mathrm{~ns}$, led to ionization; scanning the energy of the second photon while monitoring the mass signature of interest generated an ion yield curve, from which the ionization threshold was extracted.

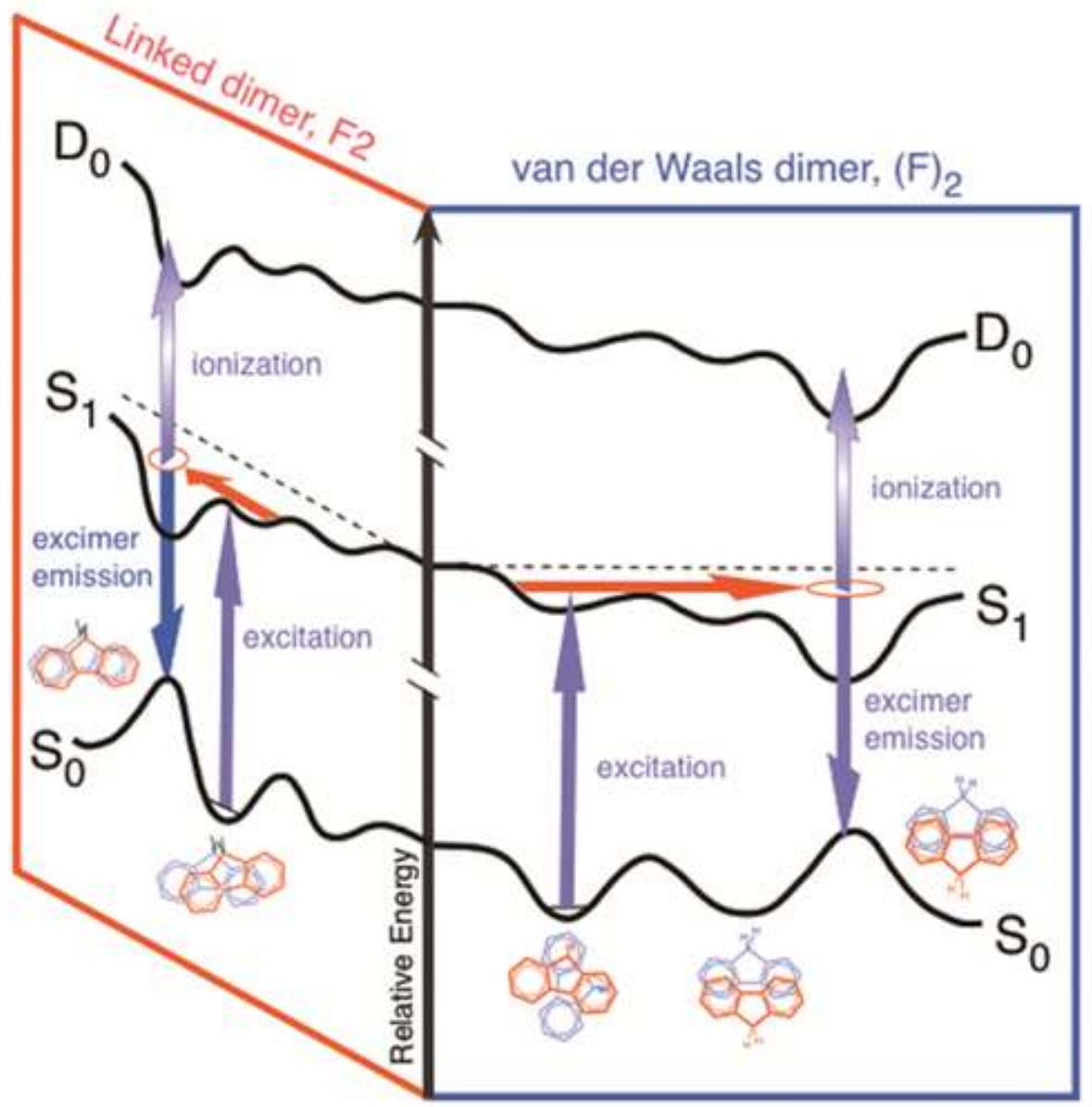

Figure 1. Experimental schematic. For both covalently linked $F 2$ and the van der Waals dimer $(F)_{2}$, excitation of the isolated dimer leads to rapid excimer formation, which is probed by monitoring emission, or by delayed ionization.

Journal of Physical Chemistry Letters, Vol 7, No. 15 (August 4, 2016): pg. 3042-3045. DOI. This article is (C) American Chemical Society and permission has been granted for this version to appear in e-Publications@Marquette. American Chemical Society does not grant permission for this article to be further copied/distributed or hosted elsewhere without the express permission from American Chemical Society. 
Gas-phase emission spectra of $F 2$ and $(F)_{2}$ are compared in Figure 2 with the solution phase spectrum of F2, measured in dichloromethane. All spectra show a broad, red-shifted feature characteristic of excimeric emission, and the lifetime of the F2 emission, of order $60 \mathrm{~ns}$, is similar to the reported lifetime (54 ns) of $(F)_{2} \cdot \underline{6}$ However, the position of the F2 emission feature is shifted to longer wavelength by some $40 \mathrm{~nm}$ from that of $(F)_{2}$, indicating significant (up to $\sim 30 \mathrm{~kJ} / \mathrm{mol}$ ) stabilization of the excimer in the covalently linked system. We suggest that this stabilization arises from the ability of the covalently linked dimer to form a perfect sandwich structure, which is not possible in the van der Waals dimer due to steric repulsion. Interestingly, the solution and gas-phase spectra of F2 are similar, revealing little solvochromatic effect.

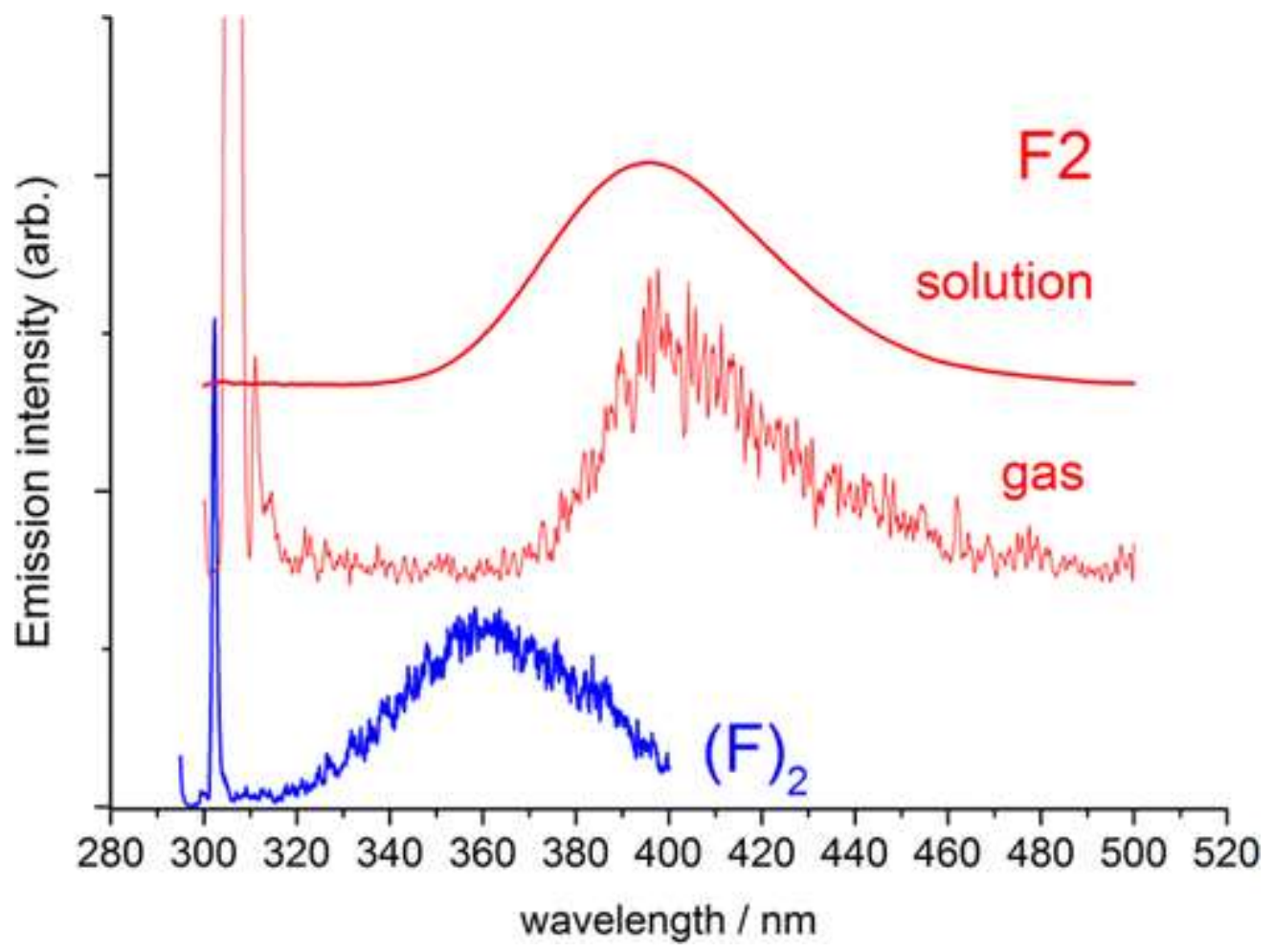

Figure 2. Emission spectra of $F 2$ and $(F)_{2}$ in the gas phase. Also shown for comparison is the solution phase spectrum of F2.

To probe the degree of stabilization of the cation radicals in the two dimers, ionization thresholds were determined using two-color ionization. Photoionization from the excimer well is expected to show favorable Franck-Condon factors, owing to the similar geometries of excimer and cation radical. However, under our conditions no 
collisional relaxation occurs on the time scale of the experiment, and ionization therefore occurs from highly excited vibrational levels in the excimer well, giving rise to a gradual onset in the dimer ion yield curves, shown in Figure 3, which compares ion yield curves for F2 and $(F)_{2}$ (upper panel) with that of the fluorene monomer. The dimers display identical ionization thresholds of $\sim 7.51(1) \mathrm{eV}$, significantly lowered by $\sim 0.38 \mathrm{eV}$ or $40 \mathrm{~kJ} / \mathrm{mol}$ relative to the monomer (7.885(5) $\mathrm{eV})$. Thus, the cation radical state is stabilized in the dimers, as expected, but surprisingly to a similar degree. This strongly suggests that, in comparison with excimer formation, stabilization of the cation radical does not require optimum overlap; that is, that the geometrical requirements for hole stabilization are less restrictive. 20 Note that the IP of F2 determined here via two-color ionization is consistent with an prior determination from photoelectron spectroscopy. 13

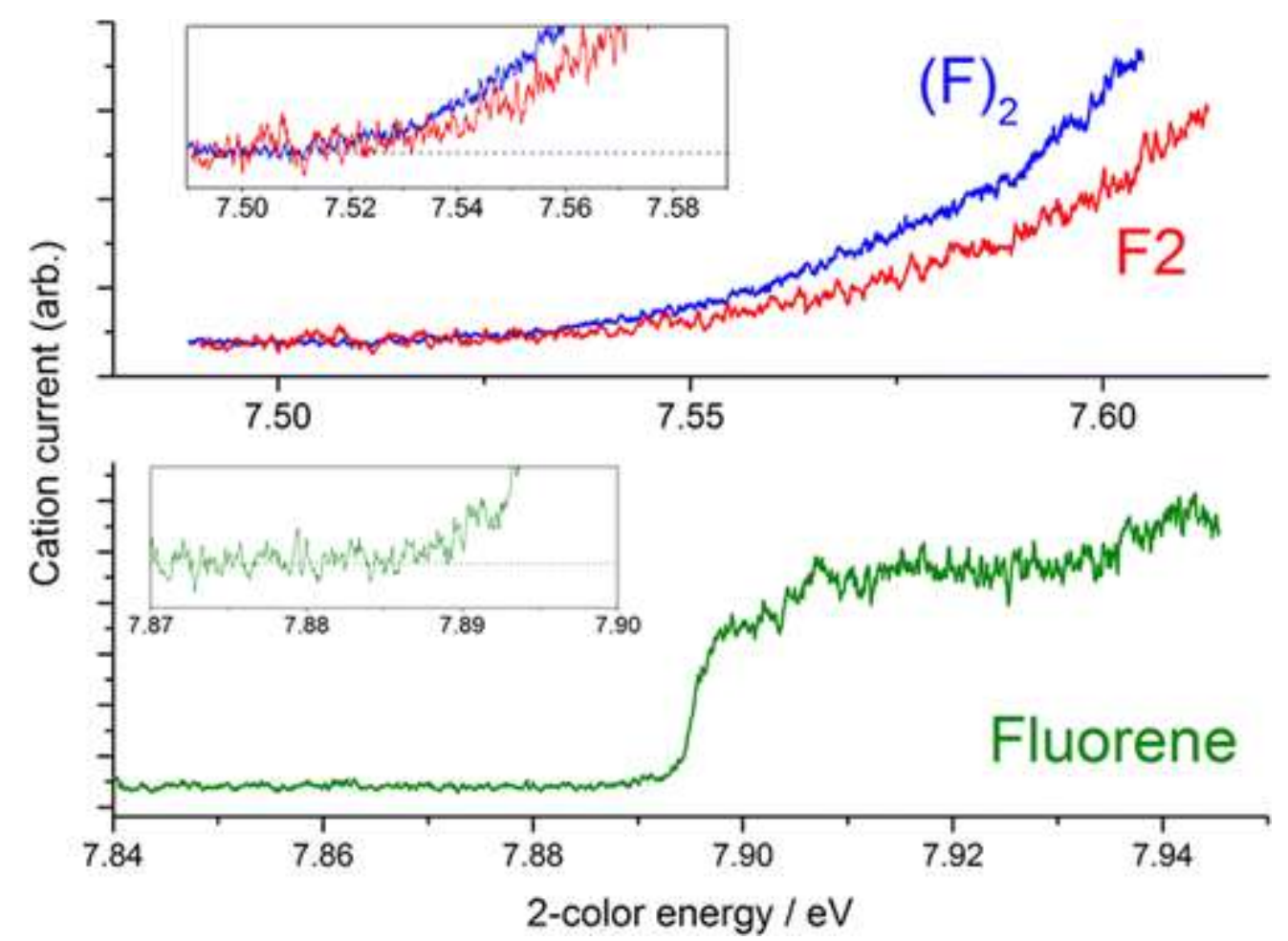

Figure 3. Ion yield curves of $(F)_{2}, F 2$ and fluorene monomer.

Our experimental findings are consistent with computational studies of the relevant potential energy surfaces. Due to the importance of electron correlation in the proper description of $\Pi$ stacking interactions, we performed a brief benchmarking study of the benzene dimer; $; \underline{21}$ details are provided in the $\underline{\mathrm{SI}}$. We found that 
accurate energies could be obtained using a simple PBEO density functional $\underline{22,23}$ augmented with the D3 version of Grimme's dispersion term, $\underline{24}$ at a fraction of the cost of more sophisticated methods (Table

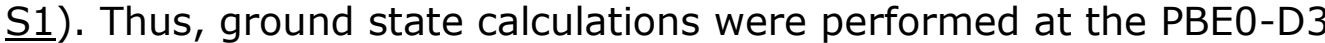
level with a def2-TZVP basis set. $\underline{25,26}$ Excited electronic states were computed with time-dependent DFT at the PBE0-D3 level with def2TZVP or def2-SV(P) basis sets. For the cation radical states, a calibrated 27-29 B1LYP functional (B1LYP-40) was employed, with a 6$31 \mathrm{G}(\mathrm{d})$ basis set; wave function stability tests were performed to ensure the absence of states with lower energy.

Figure 4 displays the energies of relevant points on the singlet PESs of $(F)_{2}$, at left, and F2. The global minimum of the van der Waals dimer corresponds to a parallel orthogonal conformer, which is consistent with the experimental finding of excitonic bands bearing nearly equal intensity (Table S2). 5 On the $\mathrm{S}_{1}$ surface, the head-to-tail sandwich excimer structure is the global minimum, lying $\sim 64 \mathrm{~kJ} / \mathrm{mol}$ below the vertical energy of the locally excited (LE) state. Vertical ionization requires $333 \mathrm{~kJ} / \mathrm{mol}$ of energy from the bottom of the excimer well.
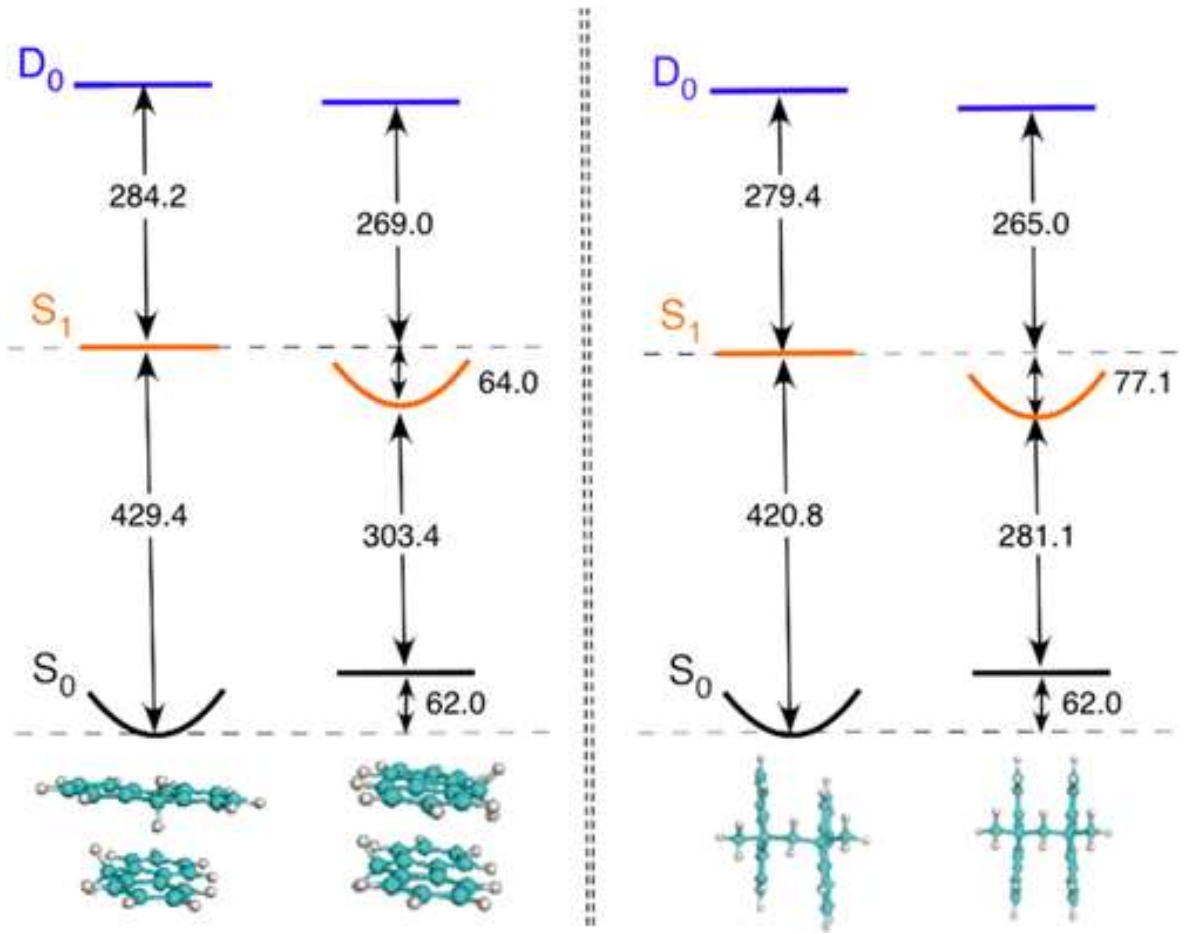

Figure 4. Calculated points on the potential energy surfaces of $(F)_{2}$ (at left) and $F 2$. Parabolas indicate where geometry optimizations were performed.

Journal of Physical Chemistry Letters, Vol 7, No. 15 (August 4, 2016): pg. 3042-3045. DOI. This article is (C) American Chemical Society and permission has been granted for this version to appear in e-Publications@Marquette. American Chemical Society does not grant permission for this article to be further copied/distributed or hosted elsewhere without the express permission from American Chemical Society. 
For the covalently linked F2, the ground state minimum is a cofacial parallel-displaced structure, and the excimer lies $\sim 77 \mathrm{~kJ} / \mathrm{mol}$ below the vertical energy of the LE state. The increased stabilization of the $\mathrm{F} 2$ excimer, by some $25 \%$, as predicted by theory is roughly consistent with the observed experimental red-shift of the excimeric emission relative to $(F)_{2}$, Figure 2 . Vertical ionization of $F 2$ requires $342 \mathrm{~kJ} / \mathrm{mol}$ of energy from the bottom of the excimer well. Thus, our calculations support the experimental finding that the excimeric state is stabilized in the covalently linked dimer, whereas the vertical ionization energies of the two dimers are predicted to be similar.

Additional insights are provided from study of the van der Waals dimer of F1; that is, the 9,9'-dimethyl derivative, details of which will be reported in a future publication. As shown in Figure 2 in the SI, gas-phase emission spectra of $(\mathrm{F} 1)_{2}$ show beautifully resolved torsional structure which affords ready assignment to the head-to-tail $n$-stacked dimer. Surprisingly, there is no evidence of excimeric emission! This is rationalized as due to the increased steric constraints imposed by the methyl substituents, which prevents a sandwich overlap of the chromophores. In contrast, the measured IP of $(F 1)_{2}$ is $7.58(1) \mathrm{eV}$, which lies above that of $F 2$ and $(F)_{2}$ but still evidence significant stabilization relative to the monomer.

These findings highlight the diverse geometrical requirements inherent to excimer formation vs cation radical stabilization in a $\Pi$ stacked bichromophore, which we have explored by exploiting the fact that processes of ionization and emission occur from the (same) excimeric state in the isolated molecules. Excimer formation, which is dominated by exciton resonance and $n$-stacking, is favored by a perfect "sandwich" overlap of the two chromophores. 30 This is maximal in the covalently linked dimer, whereas steric constraints lead the van der Waals dimer to stack in a head-to-tail arrangement (Figure 4). The geometrical requirements for cation radical stabilization, which involves significant charge transfer, are less restrictive.

In organic-based electronic devices, excimer formation serves to trap generated excitons, hindering charge separation. Understanding the geometrical requirements for excimer formation vs hole stabilization thus provides valuable insights for the design of new multichromophoric assemblies.

Journal of Physical Chemistry Letters, Vol 7, No. 15 (August 4, 2016): pg. 3042-3045. DOI. This article is (C) American Chemical Society and permission has been granted for this version to appear in e-Publications@Marquette. American Chemical Society does not grant permission for this article to be further copied/distributed or hosted elsewhere without the express permission from American Chemical Society. 
NOT THE PUBLISHED VERSION; this is the author's final, peer-reviewed manuscript. The published version may be accessed by following the link in the citation at the bottom of the page.

\section{Author Present Address}

(N.R.) Department of Chemistry, University of Massachusetts-Boston, Boston, MA 02125.

The authors declare no competing financial interest.

\section{Acknowledgment}

Support by the National Science Foundation (Grant CHE-1508677) is acknowledged. The authors acknowledge useful discussions with Prof. Qadir Timerghazin. The calculations were performed on the high-performance computing cluster Père at Marquette University funded by NSF awards OCI0923037 and CBET-0521602, and the Extreme Science and Engineering Discovery Environment (XSEDE) funded by NSF (TG-CHE130101).

\section{References}

1Hoeben, F. J.; Jonkheijm, P.; Meijer, E. W.; Schenning, A. P.About Supramolecular Assemblies of П-Conjugated Systems Chem. Rev. 2005, 105, 1491-1546, DOI: 10.1021/cr030070z

2Hirata, T.; Ikeda, H.; Saigusa, H.Dynamics of Excimer Formation and Relaxation in the T-Shaped Benzene Dimer J. Phys. Chem. A 1999, 103, 1014- 1024, DOI: $10.1021 /$ jp983814z

3 Balmer, F. A.; Trachsel, M. A.; van der Avoird, A.; Leutwyler, S.The Elusive S2 State, the S1/S2 Splitting, and the Excimer States of the Benzene Dimer J. Chem. Phys. 2015, 142, 234306, DOI: 10.1063/1.4922608

4Saigusa, H.; Lim, E. C.Localized and Delocalized Excited States of the Fluorene Dimers J. Phys. Chem. 1991, 95, 1194- 1200, DOI: 10.1021/j100156a030

${ }^{5}$ Wessel, J.; Beck, S.; Highstrete, C.Excitonic Interaction in the Fluorene Dimer J. Chem. Phys. 1994, 101, 10292-10302, DOI: 10.1063/1.467909

6Saigusa, H.; Lim, E. C.Excimer Formation in Van Der Waals Dimers and Clusters of Aromatic Molecules Acc. Chem. Res. 1996, 29, 171-178, DOI: $10.1021 / a r 950169 \mathrm{v}$

ZDuhamel, J.New Insights in the Study of Pyrene Excimer Fluorescence to Characterize Macromolecules and Their Supramolecular Assemblies in Solution Langmuir 2012, 28, 6527- 6538, DOI: 10.1021/la2047646

${ }^{8}$ Chipot, C.; Jaffe, R.; Maigret, B.; Pearlman, D. A.; Kollman, P. A.Benzene Dimer: A Good Model for $\Pi-\Pi$ Interactions in Proteins? A Comparison between the Benzene and the Toluene Dimers in the Gas Phase and in 
an Aqueous Solution J. Am. Chem. Soc. 1996, 118, 11217- 11224, DOI: $10.1021 /$ ja961379l

${ }^{9}$ Amicangelo, J. C.Theoretical Study of the Benzene Excimer Using TimeDependent Density Functional Theory J. Phys. Chem. A 2005, 109, 9174- 9182, DOI: 10.1021/jp053445o

${ }^{10}$ Sinnokrot, M. O.; Sherrill, C. D.High-Accuracy Quantum Mechanical Studies of Pi-Pi Interactions in Benzene Dimers J. Phys. Chem. A 2006, 110, 10656- 10668, DOI: $10.1021 /$ jp0610416

11Hunter, C. A.; Sanders, J. K.The Nature of Pi-Pi Interactions J. Am. Chem. Soc. 1990,112 , 5525- 5534, DOI: 10.1021/ja00170a016

$\underline{12}$ Martinez, C. R.; Iverson, B. L.Rethinking the Term Pi-Stacking Chemical Science 2012, 3, 2191- 2201, DOI: 10.1039/c2sc20045g

13 Rathore, R.; Abdelwahed, S. H.; Guzei, I. A.Synthesis, Structure, and Evaluation of the Effect of Multiple Stacking on the Electron-Donor Properties of Pi-Stacked Polyfluorenes J. Am. Chem. Soc. 2003, 125, 8712-8713, DOI: $10.1021 /$ ja035518s

${ }^{14}$ Rathore, R.; Chebny, V. J.; Abdelwahed, S. H.A Versatile and Conformationally Adaptable Fluorene-Based Receptor for Efficient Binding of Silver Cation J. Am. Chem. Soc. 2005, 127, 8012-8013, DOI: $10.1021 / \mathrm{ja0} 0519350$

$\underline{15}$ Rathore, R.; Abdelwahed, S. H.; Kiesewetter, M. K.; Reiter, R. C.; Stevenson, C. D.Intramolecular Electron Transfer in Cofacially PiStacked Fluorenes: Evidence of Tunneling J. Phys. Chem. B 2006, 110, 1536- 1540, DOI: 10.1021/jp052737m

${ }^{16}$ Chebny, V. J.; Rathore, R.Convergent Synthesis of Alternating Fluorene-PXylene Oligomers and Delineation of the (Silver) Cation-Induced Folding J. Am. Chem. Soc. 2007, 129, 8458-8465, DOI: 10.1021/ja0687522

17Nakano, T.Synthesis, Structure and Function of ח-Stacked Polymers Polym. J. 2010,42, 103-123, DOI: 10.1038/pj.2009.332

18Vura-Weis, J.; Abdelwahed, S. H.; Shukla, R.; Rathore, R.; Ratner, M. A.; Wasielewski, M. R.Crossover from Single-Step Tunneling to Multistep Hopping for Molecular Triplet Energy Transfer Science 2010, 328, 1547- 1550, DOI: $10.1126 /$ science. 1189354

19 Miyazaki, M.; Fujii, M.Real Time Observation of the Excimer Formation Dynamics of a Gas Phase Benzene Dimer by Picosecond Pump-Probe Spectroscopy Phys. Chem. Chem. Phys. 2015, 17, 25989- 25997, DOI: $10.1039 / \mathrm{C} 5 \mathrm{CP} 03010 \mathrm{~B}$

${ }^{20}$ Navale, T. S.; Thakur, K.; Vyas, V. S.; Wadumethrige, S. H.; Shukla, R.; Lindeman, S. V.; Rathore, R.Charge Delocalization in Self-Assembled Mixed-Valence Aromatic Cation Radicals Langmuir 2012, 28, 71- 83, DOI: $10.1021 / \mathrm{la} 202611 \mathrm{w}$ 
NOT THE PUBLISHED VERSION; this is the author's final, peer-reviewed manuscript. The published version may be accessed by following the link in the citation at the bottom of the page.

21 Sinnokrot, M. O.; Sherrill, C. D. Highly Accurate Coupled Cluster Potential Energy Curves for the Benzene Dimer: Sandwich, T-Shaped, and Parallel-Displaced Configurations J. Phys. Chem. A 2004, 108, 1020010207, DOI: $10.1021 /$ jp0469517

22Perdew, J. P.; Ernzerhof, M.; Burke, K.Rationale for Mixing Exact Exchange with Density Functional Approximations J. Chem. Phys. 1996, 105, 9982- 9985, DOI: 10.1063/1.472933

23 Adamo, C.; Barone, V.Accurate Excitation Energies from Time-Dependent Density Functional Theory: Assessing the PBEO Model for Organic Free Radicals Chem. Phys. Lett. 1999, 314, 152- 157, DOI: 10.1016/S0009-2614(99)01113-6

${ }^{24}$ Grimme, S.; Antony, J.; Ehrlich, S.; Krieg, H.A Consistent and Accurate Ab Initio Parametrization of Density Functional Dispersion Correction (DftD) for the 94 Elements H-Pu J. Chem. Phys. 2010, 132, 154104, DOI: $10.1063 / 1.3382344$

${ }^{25}$ Weigend, F.; Ahlrichs, R.Balanced Basis Sets of Split Valence, Triple Zeta Valence and Quadruple Zeta Valence Quality for H to Rn: Design and Assessment of Accuracy Phys. Chem. Chem. Phys. 2005, 7, 32973305, DOI: 10.1039/b508541a

26 Weigend, F.Accurate Coulomb-Fitting Basis Sets for $\mathrm{H}$ to Rn Phys. Chem. Chem. Phys. 2006, 8, 1057- 1065, DOI: 10.1039/b515623h

27Renz, M.; Theilacker, K.; Lambert, C.; Kaupp, M.A Reliable QuantumChemical Protocol for the Characterization of Organic Mixed-Valence Compounds J. Am. Chem. Soc. 2009, 131, 16292-16302, DOI: $10.1021 /$ ja9070859

28 Renz, M.; Kess, M.; Diedenhofen, M.; Klamt, A.; Kaupp, M.Reliable Quantum Chemical Prediction of the Localized/Delocalized Character of Organic Mixed-Valence Radical Anions. From Continuum Solvent Models to Direct-Cosmo-Rs J. Chem. Theory Comput. 2012, 8, 41894203, DOI: $10.1021 /$ ct300545x

${ }^{29}$ Talipov, M. R.; Boddeda, A.; Timerghazin, Q. K.; Rathore, R. Key Role of End-Capping Groups in Optoelectronic Properties of Poly-P-Phenylene Cation Radicals J. Phys. Chem. C 2014, 118, 21400- 21408, DOI: 10.1021/jp5082752

30Talipov, M. R.; Ivanov, M. V.; Reid, S. A.; Rathore, R.Two's Company, Three's a Crowd: Exciton Localization in Cofacially Arrayed Polyfluorenes J. Phys. Chem. Lett. 2016, 2915- 2920, DOI: 10.1021/acs.jpclett.6b01268

Journal of Physical Chemistry Letters, Vol 7, No. 15 (August 4, 2016): pg. 3042-3045. DOI. This article is (C) American Chemical Society and permission has been granted for this version to appear in e-Publications@Marquette. American Chemical Society does not grant permission for this article to be further copied/distributed or hosted elsewhere without the express permission from American Chemical Society. 
NOT THE PUBLISHED VERSION; this is the author's final, peer-reviewed manuscript. The published version may be accessed by following the link in the citation at the bottom of the page.

\section{Supporting Information}

The Supporting Information is available free of charge on the ACS Publications website at DOI: 10.1021/acs.jpclett.6b01201.

- Materials and methods; potential energy surface profiles for $(\mathrm{F})_{2}, \mathrm{~F} 2$ and $\mathrm{F} 2 \mathrm{H} 2 ; \mathrm{S}_{1} / \mathrm{S}_{2}$ states and $V_{\mathrm{ab}}$ coupling; additional references. ( $\underline{\mathrm{PDF}})$ 


\section{Supporting Information}

\section{First Experimental Evidence for the Diverse}

\section{Requirements of Excimer vs. Hole Stabilization}

\section{in $\pi$-Stacked Assemblies}

Neil Reilly, ${ }^{*}$ Maxim Ivanov, Brandon Uhler, Marat Talipov, Rajendra Rathore*, and Scott A. Reid*

Department of Chemistry, Marquette University, P. O. Box 1881, Milwaukee, WI 53233

\section{Corresponding Author}

* Rajendra Rathore (rajendra.rathore@marquette.edu);

Scott A. Reid (scott.reid@marquette.edu)

\section{Table of contents:}

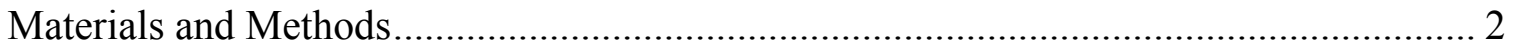

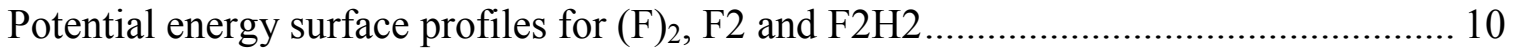

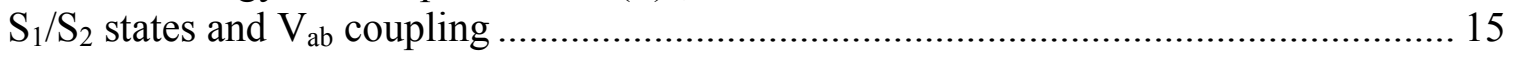

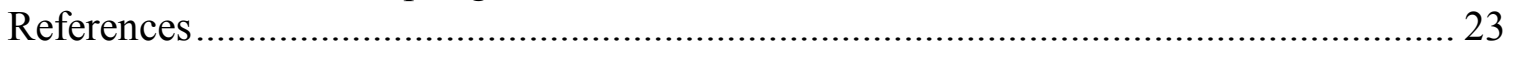




\section{Materials and Methods}

Experimental Details

Our experiments utilized two different machines, equipped with identical heat supersonic molecular beam sources, for Resonant 2-photon ionization (R2PI) ${ }^{1}$ and laser induced fluorescence (LIF) studies. The R2PI experiments were conducted in a linear $1 \mathrm{~m}$ timeof-flight mass spectrometer (TOFMS). A sample (typically 0.1-1\%) of the species of interest in a rare gas (He or Ar) was generating by passing the gas through a heated solid sample cartridge which contained roughly $50 \mathrm{mg}$ of the compound of interest trapped between loosely packed plugs of glass wool. The sample cartridge and nozzle, a solenoid-actuated pulsed valve (Parker-Hannifin), were heated up to temperatures of $250^{\circ} \mathrm{C}$ using a flexible heater element; separate thermocouples were used to monitor their temperatures. The mixture was expanded at a total pressure of typically $\sim 1-2$ bar from the $1.0 \mathrm{~mm}$ diameter nozzle, and the resulting gas pulse, of $\sim 1 \mathrm{~ms}$ duration, passed through a $1.0 \mathrm{~mm}$ diameter skimmer into the differentially pumped flight tube of a onemeter linear time-of-flight mass spectrometer. The flight tube vacuum was maintained by a $250 \mathrm{~L} / \mathrm{s}$ turbomolecular pump, and a gate valve used to isolate the detector, which was kept under vacuum at all times. The main chamber was evacuated with a waterbaffled diffusion pump (Varian VHS-4). With the nozzle on, typical pressures were $\sim 5 \mathrm{x}$ $10^{-5}$ mbar (main chamber) and $\sim 1 \times 10^{-6}$ mbar (flight tube). The background pressure in the flight tube could be lowered further by liquid nitrogen cooling of the vacuum shroud. Several types of resonant ionization experiments were conducted. First, mass-selected excitation spectra were obtained using a 1+1 R2PI scheme, with laser light near $300 \mathrm{~nm}$ generated by frequency doubling in a BBO crystal the output of a dye laser (LambdaPhysik, Scanmate 2E), pumped by the second harmonic of an Nd:YAG laser (Continuum NY-61). Typical output pulse energies were 1-2 $\mathrm{mJ}$ in the doubled beam, which was loosely focused with a 1.0 or $2.0 \mathrm{~m}$ plano-convex lens into the chamber. Ions were extracted and accelerated using a conventional three-plate stack, with the repeller plate typically held at $+2100 \mathrm{~V}$, the extractor plate at $+1950 \mathrm{~V}$, and the third plate at ground potential. The ions traversed a path of $1 \mathrm{~m}$ prior to striking a dual chevron microchannel plate detector. The detector signal was amplified (x 20) using a fast preamplifier (Femto HVA-500M-20B), and integrated using a boxcar system (Stanford Research SRS250) interfaced to a personal computer. An in-house LABVIEW program controlled data acquisition and stepped the laser wavelength; typically, the signal from twenty laser shots was averaged at each step in wavelength.

Once the mass-selected excitation spectrum was obtained using 1+1 R2PI, a second frequency doubled dye laser system (Sirah Cobra-Stretch pumped by second harmonic of Spectra-Physics INDI laser) was employed to perform two-color R2PI (i.e, 1+1' R2PI or $2 \mathrm{CR} 2 \mathrm{PI}$ ) experiments on species of interest. Here, the timing of the two lasers was controlled using an 8-channel digital pulse/delay generator (Berkeley Nucleonics 565), and the conditions (focusing, energy, temporal and spatial overlap) were optimized to enhance the ratio of 2-photon to 1-photon signal. To determine ionization potentials, the excitation laser was tuned to the origin of the species of interest, and the ionization laser was scanned through the ionization threshold. 
Hole-burning experiments were conducted to probe for the existence of multiple conformers. In these experiments, the third harmonic $(355 \mathrm{~nm})$ of a Continuum Minilite II Nd:YAG laser was used as the ionizing laser, and the INDI/Sirah system was employed as the holeburning laser, the frequency of which was set to a specific feature in the spectrum of interest. Using the divide by $n$ feature of the pulse generator, the Nd:YAG Q-switch of this laser was toggled at a repetition rate of $5 \mathrm{~Hz}$, or a duty cycle $1 / 2$ that of the nozzle and ionization laser(s), and the Q-switch delays was set so that the hole-burning laser preceded the ionizing (probe) laser(s) in time by 100-500 ns. The hole-burning spectrum was obtained using active subtraction on a shot-by-shot basis, where each shot obtained with only the ionizing (probe) laser(s) fired were subtracted from the preceding shot, where all lasers were fired. The subtracted signal was averaged over typically 20 laser shots, and recorded as the probe laser was scanned.

Laser induced fluorescence experiments were conducted in a separate chamber equipped with an identical molecular beam source. For these experiments we used the INDI/Sirah system. The timing of laser and nozzle firing was controlled by a four-channel digital pulse/delay generator (Berkeley Nucleonics model 575). The laser beam was not focused, and typical pulse energies were $\sim 0.5-1 \mathrm{~mJ}$ in a $\sim 3 \mathrm{~mm}$ diameter beam. These measurements utilized a mutually orthogonal geometry of laser, molecular beam, and detector, where the laser beam crossed the molecular beam at a distance of $\sim 15 \mathrm{~mm}(19$ nozzle diameters) downstream. Fluorescence was collected and collimated by a $f / 2.4$ plano-convex lens, and focused using a second 2 in dia. $f / 3.0$ lens either: (a) through a long-pass cutoff filter onto a photomultiplier tube detector (PMT, Oriel 77348) for monitoring total fluorescence, or (b) onto the slit of a $0.55 \mathrm{~m}$ monochromator/spectrograph (Horiba iHR550) equipped with a PMT detector (Oriel 77348). Fluorescence excitation spectra were acquired by integrating the PMT output using a gated integrator (Stanford Research SR250). The integrator output was digitized by a 12 bit ADC (Measurement Computing USB-1208FS), and passed to a computer for analysis. Typically, the signal was averaged over twenty laser shots at each step in wavelength. Data collection and laser wavelength and monochromator control was achieved using LABVIEW software. 


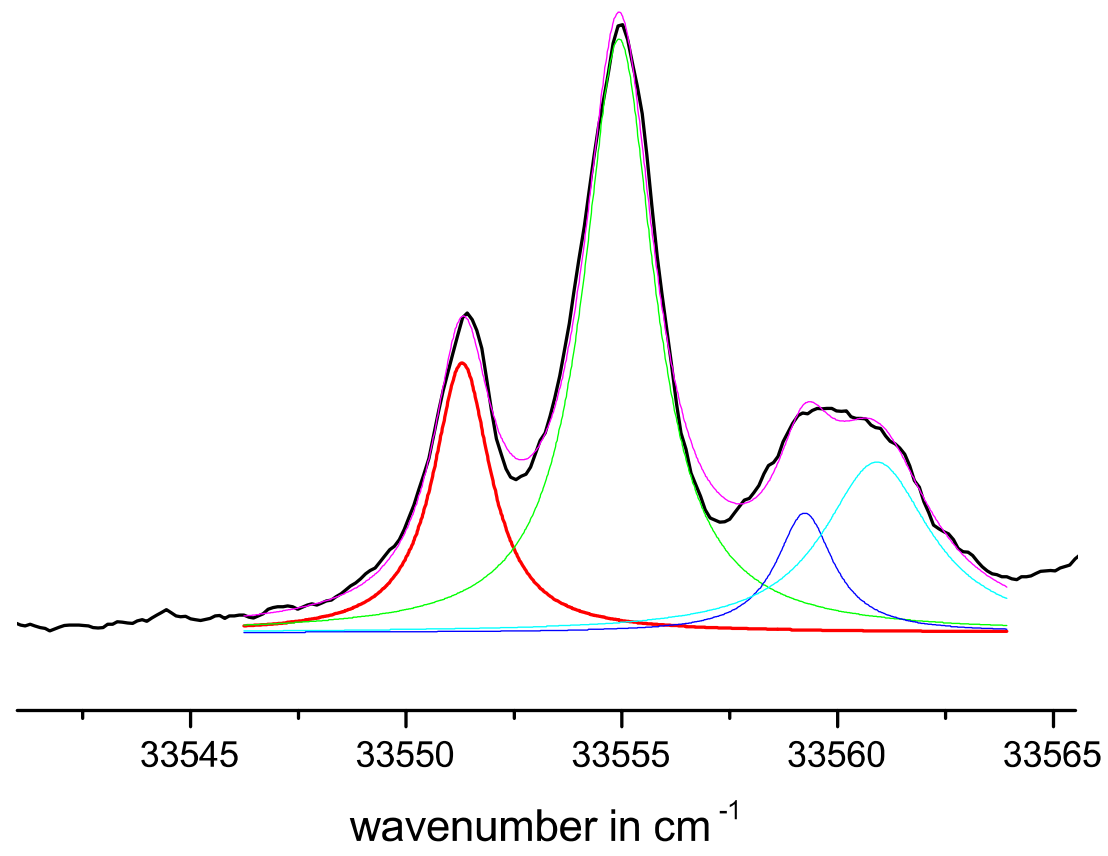

Figure S1. Lorentzian fits to the lowest energy features in the spectrum of the fluorene dimer. The origin feature is well fit by a Lorentzian with a linewidth of $1.6 \mathrm{~cm}^{-1}$, indicating a timescale of several ps for excimer formation. 


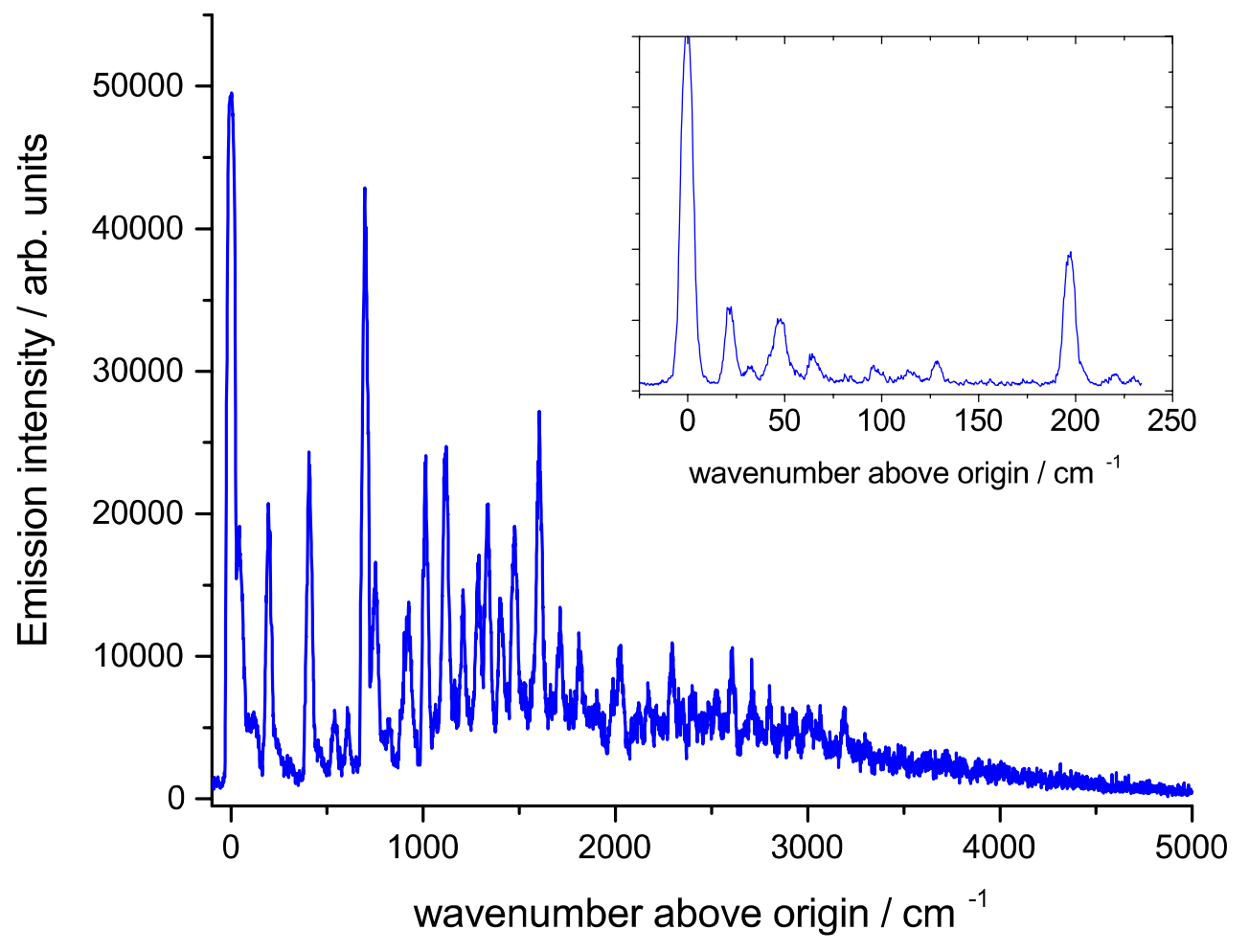

Figure S2. Emission spectra of the van der Waals dimer of 9,9'-dimethylfluorene (F1). 


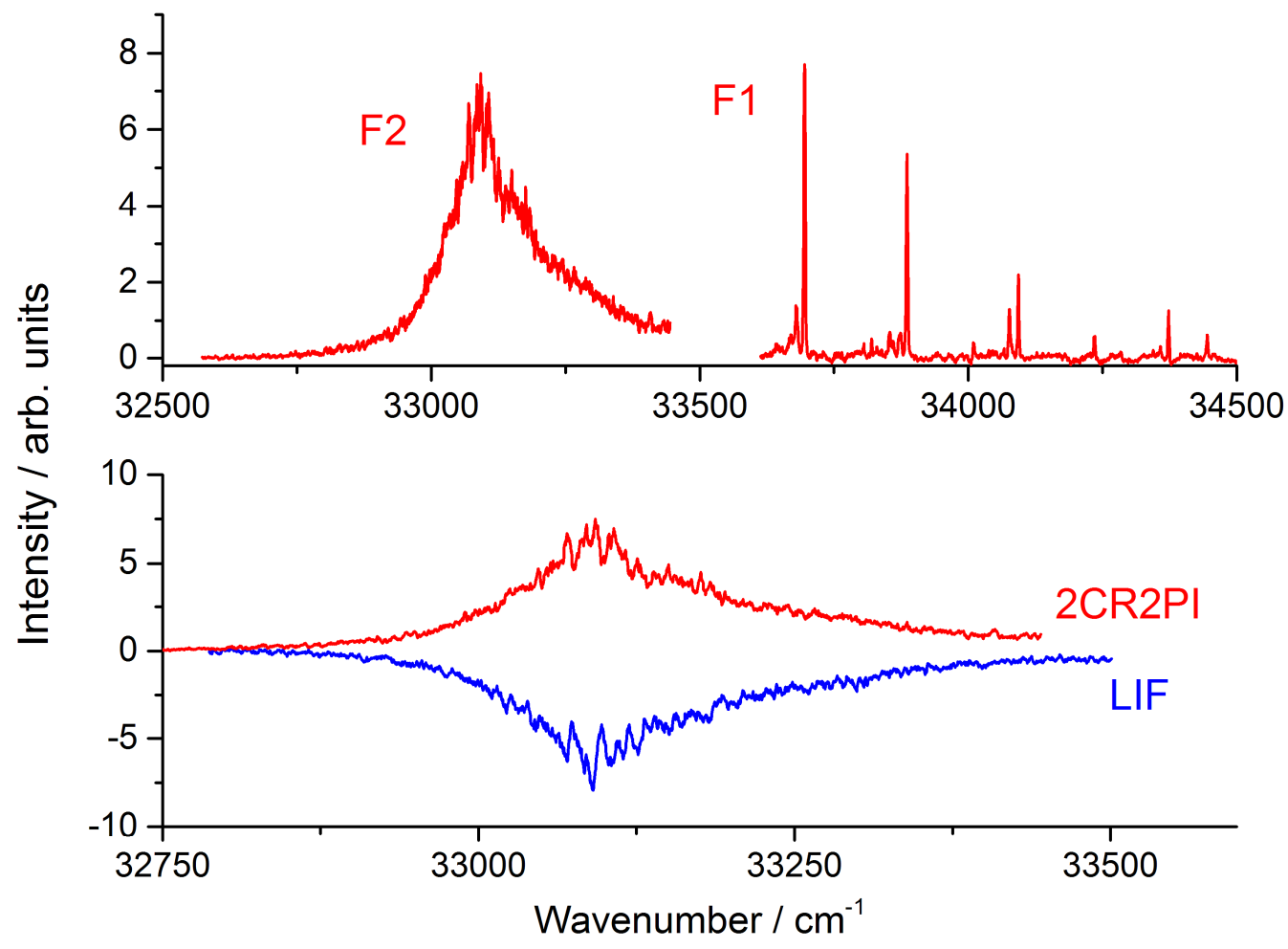

Figure S3. R2PI and LIF spectra of covalently linked F2, compared with F1. 


\section{Computational details}

All electronic structure calculations of $\mathrm{F} 2 \mathrm{H} 2, \mathrm{~F} 2$ and $(\mathrm{F})_{2}$ were performed with the Gaussian 09 package, revision D01. ${ }^{2}$ Due to the importance of the electronic correlation in the proper description of $\pi-\pi$ interactions, we performed a brief benchmarking study to evaluate several density functional theory (DFT) and ab initio methods on the example of benzene dimer in its sandwich, parallel and T-shape configurations. ${ }^{3}$ We found that accurate energy of $\pi-\pi$ stacking of two benzene molecules could be obtained by using a simple PBE0 density functional ${ }^{4,5}$ augmented with D3 version of Grimme's dispersion term $^{\underline{6}}$ only at a fraction of the computational cost of more sophisticated methods (Table S1). This observation is in agreement with the recent comprehensive benchmark study on the example of benzene-naphthalene complex. ${ }^{7}$ Thus, ground electronic state calculations of F2H2, F2 and $(\mathrm{F})_{2}$ were performed using DFT with PBE0 functional, D3 version of Grimme's dispersion and def2-TZVP basis set. ${ }^{8}, 9$ Excited electronic states were computed using the time-dependent density functional theory (TD-DFT) ${ }^{10}, \underline{11}$ method with D3 version of Grimme's dispersion at def2-TZVP and def2-SV(P) basis sets. For vertically ionized cationic states of $\mathrm{F} 2 \mathrm{H} 2, \mathrm{~F} 2$ and $(\mathrm{F})_{2}$ we used calibrated ${ }^{12-14}$ B1LYP functional ${ }^{15}$ that contains $40 \%$ contribution (denoted as B1LYP-40) of the exact exchange with $6-31 \mathrm{G}(\mathrm{d})$ basis set. ${ }^{16}$ The wave function stability tests were performed to ensure absence of solutions with lower energy. ${ }^{17,} \underline{18}$ The values of $\left\langle S^{2}>\right.$ operator after spin annihilation were confirmed to be close to the expectation value of 0.75 , thus indicating that spin contamination was not an issue for the performed calculations. To confirm that the structures correspond to the minimum on the ground and excited electronic PES we performed geometry optimizations and Hessian matrix calculations at PBE0-D3/def2SV(P) level of theory. In all DFT calculations, ultrafine Lebedev's grid was used with 99 radial shells per atom and 590 angular points in each shell. Tight cutoffs on forces and atomic displacement were used to determine convergence in geometry optimization procedure. The nudged elastic band $(\mathrm{NEB})^{19}$ method was used to estimate the upper boundary of the transition state between tilted orthogonal and sandwich structures on the first excited (S1) PES (Figure S3). NEB was used as implemented in DL-FIND code ${ }^{20}$ with the in-house developed interface to split NEB images calculations across the nodes of computational cluster. ${ }^{21}$ 
Table S1. Benchmarking of different methods to compute interaction energy in benzene dimer (in $\mathrm{kcal} / \mathrm{mol}$ ). Calculations at $\operatorname{CCSD}(\mathrm{T}) /$ aug-cc-pVQZ were taken as a reference. ${ }^{3}$

\begin{tabular}{ccccc} 
Theory & Sandwich & Parallel & T-shaped & RMSD \\
\hline CCSD(T)/aug-cc-pVQZ & -1.7 & -2.62 & -2.61 & - \\
\hline CCSD/6-31G(d) & -1.95 & -3.08 & -3.33 & 0.51 \\
CCSD/cc-pVDZ & -0.58 & -1.46 & -2.37 & 0.95 \\
CCSD-F12a/aug-cc-pVDZ & -1.3 & -2.19 & -2.51 & 0.35 \\
CCSD-F12b/aug-cc-pVDZ & -1.17 & -2.05 & -2.46 & 0.46 \\
CCSD-F12a/aug-cc-pVTZ & -0.86 & -1.71 & -2.2 & 0.75 \\
CCSD-F12b/aug-cc-pVTZ & -0.9 & -1.77 & -2.27 & 0.71 \\
CCSD(T)-F12a/ aug-cc- & & & & \\
pVDZ & -2.37 & -3.47 & -3.4 & 0.77 \\
CCSD(T)-F12b/aug-cc- & & & & \\
pVDZ & -2.24 & -3.33 & -3.36 & 0.67 \\
CCSD(T)-F12a/aug-cc- & & & & \\
pVTZ & -1.95 & -2.96 & -3.01 & 0.33 \\
CCSD(T)-F12b/aug-cc- & & & & \\
pVTZ & -1.99 & -3.02 & -3.08 & 0.39 \\
M062x/aug-cc-pVDZ & -1.65 & -3.48 & -3.18 & 0.6 \\
PBE0-D3/6-311+G(d,f) & -2.25 & -3.54 & -3.64 & 0.86 \\
PBE0-D3/def2-SVP & -2.29 & -3.33 & -3.44 & 0.72 \\
PBE0-D3/def2-TZVP & -1.73 & -2.68 & -3.05 & 0.26 \\
PBE0-D3/def2-TZVPP & -1.73 & -2.65 & -3.00 & 0.23 \\
PBE0-D3/def2-TZVPPD & -1.78 & -2.64 & -2.97 & 0.21 \\
wB97XD/aug-cc-pVDZ & -2.60 & -4.06 & -3.68 & 1.16 \\
B3LYP/aug-cc-pVDZ & 2.24 & 1.68 & -0.08 & 3.67 \\
SAPT0/aug-cc-pVDZ & -1.14 & -2.37 & -2.52 & 0.36 \\
& & & &
\end{tabular}




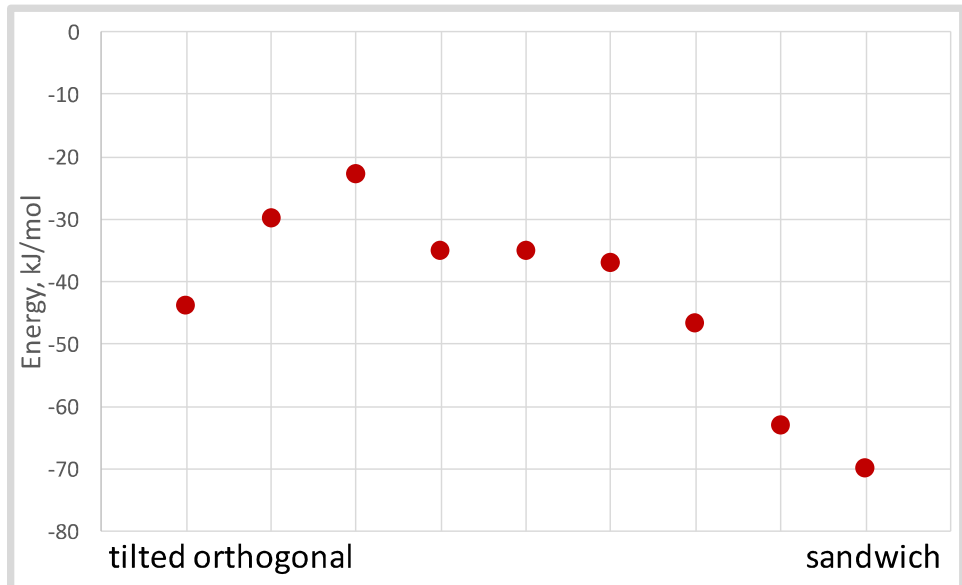

Figure S3. Nudged elastic band pathway between tilted orthogonal and sandwich structures on the excited $\left(\mathrm{S}_{1}\right)$ PES using PBE0-D3/def-SV(P). Energies are in $\mathrm{kcal} / \mathrm{mol}$ relative to the vertically excited energy of the parallel orthogonal structure. 
Potential energy surface profiles for $(\mathrm{F})_{2}, \mathrm{~F} 2$ and $\mathrm{F} 2 \mathrm{H} 2$

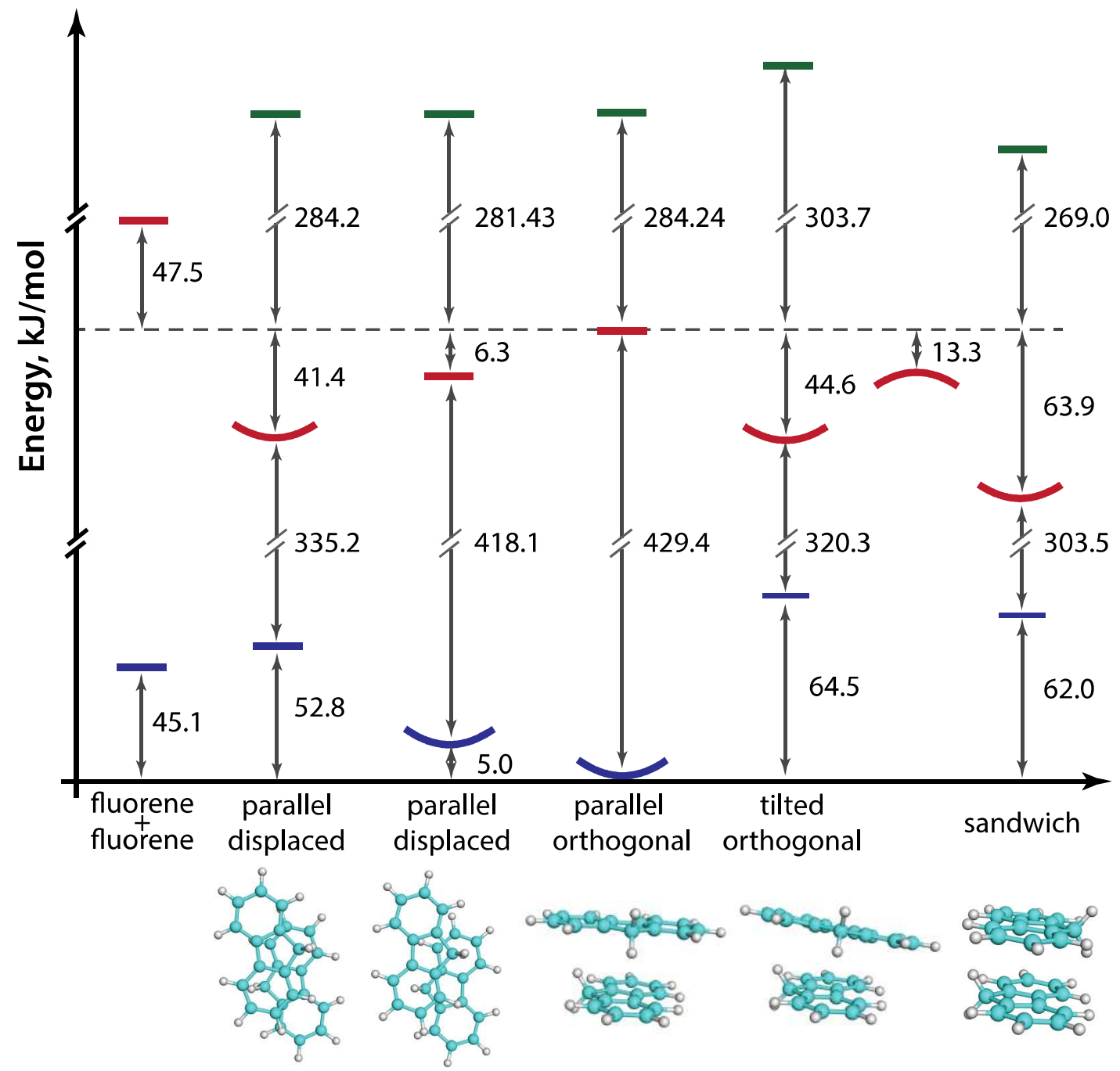

Figure S4. Calculated stationary points of the fluorene dimer, $(\mathrm{F})_{2}$, in ground (S0), first excited (S1) and ionized (D0) state using PBE0-D3/def2-TZVP. 


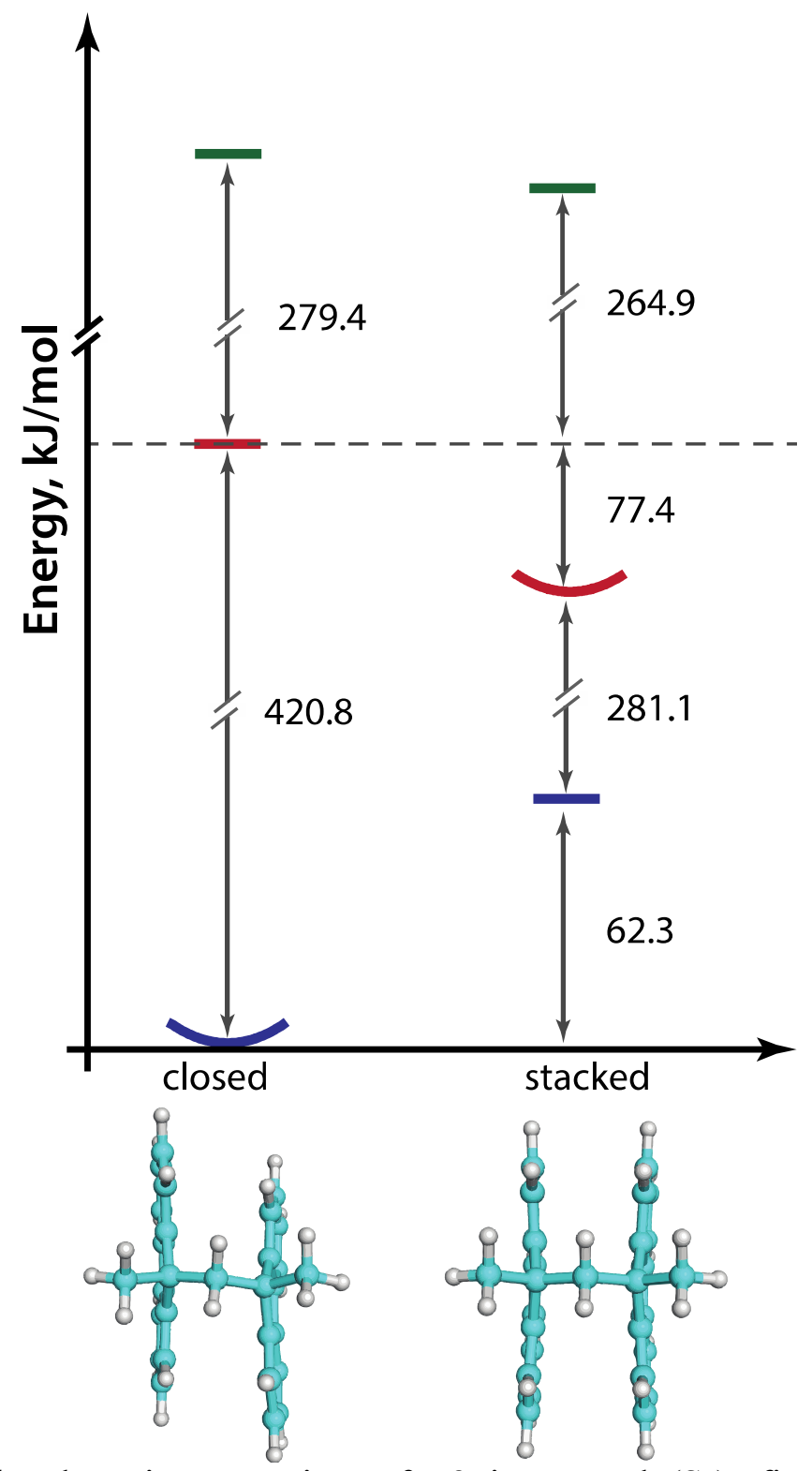

Figure S5. Calculated stationary points of $F 2$ in ground $\left(\mathrm{S}_{0}\right)$, first excited $\left(\mathrm{S}_{1}\right)$ and ionized $\left(\mathrm{D}_{0}\right)$ state using PBE0-D3/def2-TZVP. 


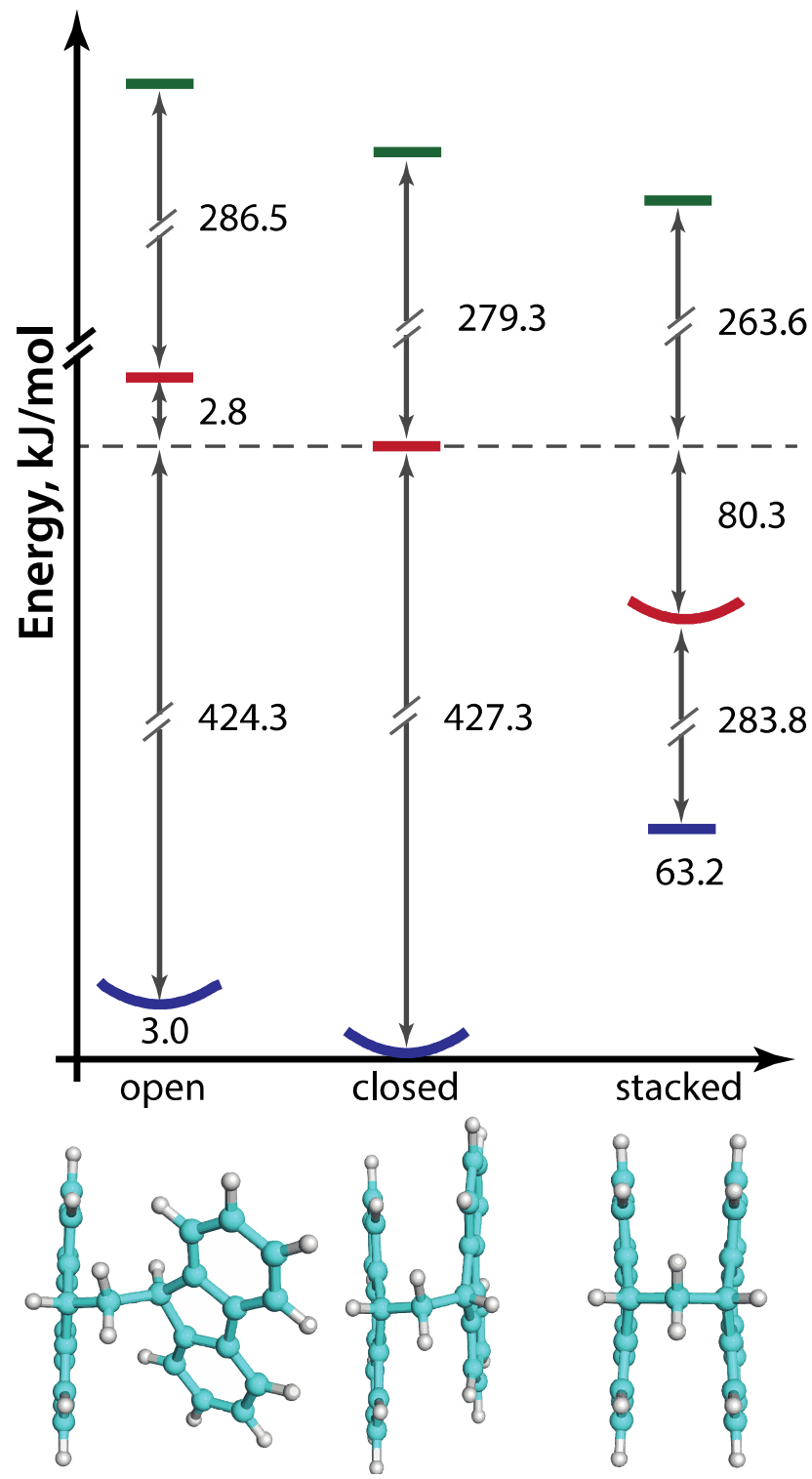

Figure S6. Calculated stationary points of $\mathrm{F} 2 \mathrm{H} 2$ in ground $\left(\mathrm{S}_{0}\right)$, first excited $\left(\mathrm{S}_{1}\right)$ and ionized $\left(\mathrm{D}_{0}\right)$ state using PBE0-D3/def2-TZVP. 
Table S2. Energies of ground $\left(S_{0}\right)$, excited $\left(S_{1}\right)$ and cationic $\left(D_{0}\right)$ states of $(F)_{2}$ calculated at PBE0-D3/def2-TZVP level of theory relative to the energy of parallel orthogonal structure (global minimum on ground electronic state). All values are in $\mathrm{kJ} / \mathrm{mol}$.

\begin{tabular}{cccccccc}
\hline & F+F* & $\begin{array}{c}\text { parallel } \\
\text { displaced S1 }\end{array}$ & $\begin{array}{c}\text { parallel } \\
\text { displaced S0 }\end{array}$ & $\begin{array}{c}\text { parallel } \\
\text { orthogonal }\end{array}$ & $\begin{array}{c}\text { tilted } \\
\text { orthogonal }\end{array}$ & TS & sandwich \\
\hline D0 & 782.4 & 713.6 & 710.8 & 713.6 & 733.1 & & 698.4 \\
\hline S1 & 477.0 & 388.0 & 423.1 & 429.4 & 384.8 & 416.2 & 365.5 \\
\hline S0 & 45.1 & 52.8 & 5.0 & 0.0 & 64.5 & 47.7 & 62.0 \\
\hline
\end{tabular}

Table S3. Energies of ground $\left(S_{0}\right)$, excited $\left(S_{1}\right)$ and cationic $\left(D_{0}\right)$ states of $(F)_{2}$ calculated at PBE0-D3/def2-SV(P) level of theory relative to the energy of parallel orthogonal structure (global minimum on ground electronic state). All values are in $\mathrm{kJ} / \mathrm{mol}$.

\begin{tabular}{cccccccc}
\hline & F+F* & $\begin{array}{c}\text { parallel } \\
\text { displaced S1 }\end{array}$ & $\begin{array}{c}\text { parallel } \\
\text { displaced S0 }\end{array}$ & $\begin{array}{c}\text { parallel } \\
\text { orthogonal }\end{array}$ & $\begin{array}{c}\text { tilted } \\
\text { orthogonal }\end{array}$ & TS & sandwich \\
\hline D0 & 795.2 & 715.3 & 713.0 & 715.2 & 738.6 & & 696.6 \\
\hline S1 & 491.2 & 387.6 & 427.0 & 434.3 & 382.5 & 411.4 & 364.1 \\
\hline S0 & 53.6 & 56.6 & 6.5 & 0.0 & 76.3 & 35.4 & 62.2 \\
\hline
\end{tabular}

Table S4. Energies of ground $\left(\mathrm{S}_{0}\right)$, excited $\left(\mathrm{S}_{1}\right)$ and cationic $\left(\mathrm{D}_{0}\right)$ states of $(\mathrm{F})_{2}$ calculated at BLYP40/6-31G(d) level of theory relative to the energy of parallel orthogonal structure (global minimum on ground electronic state). All values are in $\mathrm{kJ} / \mathrm{mol}$.

\begin{tabular}{|c|c|c|c|c|c|c|c|}
\hline & $\mathrm{F}+\mathrm{F}^{*}$ & $\begin{array}{c}\text { parallel } \\
\text { displaced S1 }\end{array}$ & $\begin{array}{c}\text { parallel } \\
\text { displaced SO }\end{array}$ & $\begin{array}{c}\text { parallel } \\
\text { orthogonal }\end{array}$ & $\begin{array}{c}\text { tilted } \\
\text { orthogonal }\end{array}$ & TS & sandwich \\
\hline DO & 705.7 & 683.7 & 682.5 & 685.2 & 690.4 & & 680.2 \\
\hline S1 & 453.3 & 432.1 & 467.3 & 471.9 & 434.3 & & 420.7 \\
\hline SO & 5.2 & 48.3 & -2.3 & 0.0 & 40.3 & & 68.4 \\
\hline
\end{tabular}

Table S5. Energies of ground ground $\left(\mathrm{S}_{0}\right)$, excited $\left(\mathrm{S}_{1}\right)$ and cationic $\left(\mathrm{D}_{0}\right)$ states of $\mathrm{F} 2 \mathrm{H} 2$ calculated at PBE0-D3/def2-TZVP level of theory relative to the energy of the closed structure (global minimum on ground electronic state). All values are in $\mathrm{kJ} / \mathrm{mol}$.

\begin{tabular}{cccc}
\hline & closed & open & stacked \\
\hline D0 & 706.6 & 716.7 & 690.9 \\
\hline S1 & 427.3 & 430.2 & 347.0 \\
\hline S0 & 0.0 & 3.0 & 63.2 \\
\hline
\end{tabular}

Table S6. Energies of ground $\left(\mathrm{S}_{0}\right)$, excited $\left(\mathrm{S}_{1}\right)$ and cationic $\left(\mathrm{D}_{0}\right)$ states of $\mathrm{F} 2 \mathrm{H} 2$ calculated at PBE0-D3/def2-SV(P) level of theory relative to the energy of the closed structure (global minimum on ground electronic state). All values are in $\mathrm{kJ} / \mathrm{mol}$.

\begin{tabular}{cccc}
\hline & closed & open & stacked \\
\hline D0 & 705.2 & 724.7 & 691.0 \\
\hline S1 & 425.9 & 439.8 & 346.8 \\
\hline S0 & 0.0 & 9.4 & 64.0 \\
\hline
\end{tabular}


Table S7. Energies of ground $\left(\mathrm{S}_{0}\right)$, excited $\left(\mathrm{S}_{1}\right)$ and cationic $\left(\mathrm{D}_{0}\right)$ states of $\mathrm{F} 2 \mathrm{H} 2$ calculated at BLYP40/6-31G(d) level of theory relative to the energy of the closed structure (global minimum on ground electronic state). All values are in $\mathrm{kJ} / \mathrm{mol}$.

\begin{tabular}{cccc}
\hline & closed & open & stacked \\
\hline D0 & 678.9 & 677.0 & 665.8 \\
\hline S1 & 465.7 & 456.2 & 395.6 \\
\hline S0 & 0.0 & -12.4 & 64.3 \\
\hline
\end{tabular}

Table S8. Energies of ground $\left(\mathrm{S}_{0}\right)$, excited $\left(\mathrm{S}_{1}\right)$ and cationic $\left(\mathrm{D}_{0}\right)$ states of $\mathrm{F} 2$ calculated at PBE0-D3/def2-TZVP level of theory relative to the energy of the closed structure. All values are in $\mathrm{kJ} / \mathrm{mol}$.

\begin{tabular}{lrr}
\hline & \multicolumn{1}{c}{ closed } & \multicolumn{1}{c}{ stacked } \\
\hline D0 & 700.2 & 685.7 \\
\hline S1 & 420.8 & 343.4 \\
\hline S0 & 0.0 & 62.3 \\
\hline
\end{tabular}

Table S9. Energies of ground $\left(\mathrm{S}_{0}\right)$, excited $\left(\mathrm{S}_{1}\right)$ and cationic $\left(\mathrm{D}_{0}\right)$ states of $\mathrm{F} 2$ calculated at PBE0-D3/def2-SV(P) level of theory relative to the energy of the closed structure. All values are in $\mathrm{kJ} / \mathrm{mol}$.

\begin{tabular}{lrr}
\hline & \multicolumn{1}{c}{ closed } & \multicolumn{1}{c}{ stacked } \\
\hline D0 & 699.0 & 686.0 \\
\hline S1 & 420.7 & 343.8 \\
\hline S0 & 0.0 & 63.8
\end{tabular}

Table S10. Energies of ground $\left(S_{0}\right)$, excited $\left(S_{1}\right)$ and cationic $\left(D_{0}\right)$ states of $F 2$ calculated at BLYP40/6-31G(d) level of theory relative to the energy of the closed structure. All values are in $\mathrm{kJ} / \mathrm{mol}$.

\begin{tabular}{lrr}
\hline & \multicolumn{1}{c}{ closed } & \multicolumn{1}{c}{ stacked } \\
\hline D0 & 678.7 & 660.2 \\
\hline S1 & 460.9 & 391.2 \\
\hline S0 & 0.0 & 63.0 \\
\hline
\end{tabular}




\section{$S_{1} / S_{2}$ states and $V_{a b}$ coupling}

Tables below contain the energy of states $S_{1}$ and $S_{2}$ relative to the $S_{0}$ state for the corresponding geometry, coupling $\mathrm{V}_{\mathrm{ab}}$, oscillator strength $f$ for each transition, number of orbitals involved in the transition and corresponding coefficients.

Table S11. F2 closed conformation at TD PBE0-GD3/def2-TZVP

\begin{tabular}{cccccc}
\hline & $\mathrm{E}, \mathrm{eV}$ & $\mathrm{E}, \mathrm{kJ} / \mathrm{mol}$ & $\boldsymbol{f}$ & transition & coeff. \\
\hline $\mathrm{S}_{1}$ & 4.361 & 420.8 & 0.0080 & $99->100$ & 0.68185 \\
\hline & & & & $98->100$ & 0.52189 \\
\cline { 5 - 6 } $\mathrm{S}_{2}$ & 4.452 & 429.6 & 0.0155 & $98->102$ & -0.11376 \\
\cline { 5 - 6 } & & & & $99->101$ & -0.4496 \\
\hline $\mathrm{V}_{\mathrm{ab}}$ & 0.046 & 4.4 & & & \\
\end{tabular}

Table S12. F2 stacked conformation at TD PBE0-GD3/def2-TZVP

\begin{tabular}{|c|c|c|c|c|c|}
\hline & $E, \mathrm{eV}$ & $\mathrm{E}, \mathrm{kJ} / \mathrm{mol}$ & $f$ & transition & coeff. \\
\hline $\mathbf{S}_{1}$ & 2.914 & 281.2 & 0.0000 & 99 -> 100 & -0.7048 \\
\hline \multirow{2}{*}{$\mathbf{S}_{2}$} & \multirow{2}{*}{3.480} & \multirow{2}{*}{335.7} & \multirow{2}{*}{0.0000} & $96->100$ & 0.16872 \\
\hline & & & & $99->101$ & -0.68259 \\
\hline $\mathbf{V}_{\mathrm{ab}}$ & 0.283 & 27.3 & & & \\
\hline
\end{tabular}

Table S13. F2 closed conformation at TD PBE0-GD3/def2-SV(P)

\begin{tabular}{cccccc} 
& $\mathrm{E}, \mathrm{eV}$ & $\mathrm{E}, \mathrm{kJ} / \mathrm{mol}$ & $\boldsymbol{f}$ & transition & coeff. \\
\hline $\mathrm{S}_{1}$ & 4.3602 & 420.7 & 0.0064 & $99->100$ & 0.68318 \\
\hline & & & & $98->100$ & 0.50821 \\
\cline { 5 - 6 } $\mathrm{S}_{2}$ & 4.4625 & 430.6 & 0.0161 & $98->102$ & 0.11735 \\
\cline { 5 - 6 } & & & & $99->101$ & 0.46014 \\
\hline $\mathrm{V}_{\mathrm{ab}}$ & 0.051 & 4.9 & & & \\
\hline
\end{tabular}

Table S14. F2 stacked conformation at TD PBE0-GD3/def2-SV(P)

\begin{tabular}{cccccc}
\hline & $\mathrm{E}, \mathbf{e V}$ & $\mathrm{E}, \mathrm{kJ} / \mathrm{mol}$ & $\boldsymbol{f}$ & transition & coeff. \\
\hline $\mathrm{S}_{1}$ & 2.903 & 280.1 & 0.0000 & $99->100$ & 0.70496 \\
\hline $\mathrm{S}_{\mathbf{2}}$ & 3.524 & 340.0 & 0.0000 & $97->100$ & -0.20779 \\
\cline { 5 - 6 } & & & & $99->101$ & -0.67134 \\
\hline $\mathrm{V}_{\mathrm{ab}}$ & 0.311 & 30.0 & & & \\
\hline
\end{tabular}

Table S15. F2 closed conformation at BLYP40/6-31G(d)

\begin{tabular}{cccccc}
\hline & $\mathrm{E}, \mathrm{eV}$ & $\mathrm{E}, \mathrm{kJ} / \mathrm{mol}$ & $\boldsymbol{f}$ & transition & coeff. \\
\hline $\mathrm{S}_{1}$ & 4.777 & 460.9 & 0.0292 & $98->100$ & 0.5473 \\
\hline
\end{tabular}




\begin{tabular}{|c|c|c|c|c|c|}
\hline & & & & 99 -> 101 & -0.40158 \\
\hline \multirow{6}{*}{$\mathbf{S}_{2}$} & \multirow{6}{*}{4.902} & \multirow{6}{*}{473.0} & \multirow{6}{*}{0.4483} & $94->100$ & -0.12657 \\
\hline & & & & 96 ->101 & -0.10767 \\
\hline & & & & $96->103$ & 0.1037 \\
\hline & & & & $98->101$ & -0.44226 \\
\hline & & & & $99->100$ & 0.45431 \\
\hline & & & & $99->102$ & 0.16183 \\
\hline $\mathbf{V}_{\mathrm{ab}}$ & 0.062 & 6.0 & & & \\
\hline
\end{tabular}

Table S16. F2 stacked conformation at BLYP40/6-31G(d)

\begin{tabular}{|c|c|c|c|c|c|}
\hline & $E, e V$ & $\mathrm{E}, \mathrm{kJ} / \mathrm{mol}$ & $f$ & transition & coeff. \\
\hline$S_{1}$ & 3.402 & 328.2 & 0.000 & $99->100$ & 0.70055 \\
\hline \multirow{2}{*}{$S_{2}$} & \multirow{2}{*}{4.083} & \multirow{2}{*}{393.9} & \multirow{2}{*}{0.000} & $96->100$ & 0.22527 \\
\hline & & & & $99->101$ & 0.65369 \\
\hline $\mathrm{V}_{\mathrm{ab}}$ & 0.341 & 32.9 & & & \\
\hline
\end{tabular}

Table S17. F2H2 closed conformation at TD PBE0-GD3/def2-TZVP

\begin{tabular}{|c|c|c|c|c|c|}
\hline & $E, e V$ & $\mathrm{E}, \mathrm{kJ} / \mathrm{mol}$ & $f$ & transition & coeff. \\
\hline$S_{1}$ & 4.429 & 427.3 & 0.0097 & $90->92$ & 0.67692 \\
\hline \multirow{4}{*}{$S_{2}$} & \multirow{4}{*}{4.460} & \multirow{4}{*}{430.3} & \multirow{4}{*}{0.0082} & $90->93$ & -0.40695 \\
\hline & & & & $90->95$ & -0.10213 \\
\hline & & & & 91 -> 92 & 0.44265 \\
\hline & & & & 91 -> 94 & -0.3342 \\
\hline
\end{tabular}

Table S18. F2H2 open conformation at TD PBE0-GD3/def2-TZVP

\begin{tabular}{|c|c|c|c|c|c|}
\hline & $E, e V$ & $\mathrm{E}, \mathrm{kJ} / \mathrm{mol}$ & $f$ & transition & coeff. \\
\hline $\mathbf{S}_{1}$ & 4.427 & 427.1 & 0.0259 & 91 -> 92 & 0.69982 \\
\hline \multirow{9}{*}{$S_{2}$} & \multirow{9}{*}{4.592} & \multirow{9}{*}{443.1} & \multirow{9}{*}{0.0629} & $86->92$ & 0.14388 \\
\hline & & & & 88 -> 92 & 0.11401 \\
\hline & & & & 88 -> 93 & -0.12438 \\
\hline & & & & $90->92$ & 0.40918 \\
\hline & & & & 90 -> 93 & 0.19802 \\
\hline & & & & $90->94$ & 0.20976 \\
\hline & & & & 91 -> 93 & -0.23746 \\
\hline & & & & 91 -> 94 & 0.28089 \\
\hline & & & & 91 -> 95 & 0.17168 \\
\hline$V_{a b}$ & 0.083 & 8.0 & & & \\
\hline
\end{tabular}


Table S19. F2H2 stacked conformation at TD PBE0-GD3/def2-TZVP

\begin{tabular}{cccccc} 
& $\mathrm{E}, \mathrm{eV}$ & $\mathrm{E}, \mathrm{kJ} / \mathrm{mol}$ & $\boldsymbol{f}$ & transition & coeff. \\
\hline $\mathrm{S}_{1}$ & 2.943 & 283.9 & 0.0000 & $91->92$ & 0.70474 \\
\hline $\mathrm{S}_{2}$ & 3.403 & 328.3 & 0.0000 & $88->92$ & 0.14146 \\
\cline { 5 - 6 } & & & & $91->93$ & 0.68904 \\
\hline $\mathrm{V}_{\mathrm{ab}}$ & 0.230 & 22.2 & & & \\
\hline
\end{tabular}

Table S20. F2H2 closed conformation at TD PBE0-GD3/def2-SV(P)

\begin{tabular}{|c|c|c|c|c|c|}
\hline & $E, e V$ & $\mathrm{E}, \mathrm{kJ} / \mathrm{mol}$ & $f$ & transition & coeff. \\
\hline S1 & 4.414 & 425.9 & 0.0072 & $91->92$ & 0.68437 \\
\hline \multirow{3}{*}{ S2 } & \multirow{3}{*}{4.472} & \multirow{3}{*}{431.5} & \multirow{3}{*}{0.0138} & $90->92$ & 0.50745 \\
\hline & & & & $90->94$ & 0.23193 \\
\hline & & & & $91->93$ & 0.40925 \\
\hline
\end{tabular}

$\begin{array}{lll}\text { Vab } & 0.029 \quad 2.8\end{array}$

Table S21. F2H2 open conformation at TD PBE0-GD3/def2-SV(P)

\begin{tabular}{|c|c|c|c|c|c|}
\hline & $E, e V$ & $\mathrm{E}, \mathrm{kJ} / \mathrm{mol}$ & $f$ & transition & coeff. \\
\hline S1 & 4.461 & 430.4 & 0.0263 & 91 -> 92 & 0.70089 \\
\hline \multirow{9}{*}{ S2 } & \multirow{9}{*}{4.664} & \multirow{9}{*}{450.0} & \multirow{9}{*}{0.1021} & 86 -> 92 & 0.12853 \\
\hline & & & & 88 -> 92 & 0.13176 \\
\hline & & & & 88 -> 93 & -0.11806 \\
\hline & & & & $90->92$ & 0.48891 \\
\hline & & & & $90->93$ & 0.11338 \\
\hline & & & & $90->94$ & 0.15406 \\
\hline & & & & 91 -> 93 & -0.27263 \\
\hline & & & & 91 -> 94 & 0.20394 \\
\hline & & & & 91 -> 95 & -0.15107 \\
\hline Vab & 0.102 & 9.8 & & & \\
\hline
\end{tabular}

Table S22. F2H2 stacked conformation at TD PBE0-GD3/def2-SV(P)

\begin{tabular}{cccccc}
\hline & $\mathrm{E}, \mathrm{eV}$ & $\mathrm{E}, \mathrm{kJ} / \mathrm{mol}$ & $\boldsymbol{f}$ & transition & coeff. \\
\hline $\mathrm{S}_{1}$ & 2.932 & 282.9 & 0.0000 & $91->92$ & 0.70479 \\
\hline $\mathrm{S}_{\mathbf{2}}$ & 3.468 & 334.6 & 0.0000 & $88->92$ & -0.17679 \\
\cline { 5 - 6 } & & & & $91->93$ & 0.68031 \\
\hline $\mathrm{V}_{\mathrm{ab}}$ & 0.268 & 25.8 & & & \\
\hline
\end{tabular}

Table S23. F2H2 closed conformation at BLYP40/6-31G(d)

\begin{tabular}{cccccc}
\hline & $\mathrm{E}, \mathrm{eV}$ & $\mathrm{E}, \mathrm{kJ} / \mathrm{mol}$ & $\mathbf{f}$ & transition & coeff. \\
\hline \multirow{2}{*}{$\mathrm{S}_{1}$} & 4.827 & \multirow{2}{*}{465.7} & 0.0365 & $90->92$ & 0.54521 \\
\cline { 5 - 6 } & & & & $91>93$ & -0.40578 \\
\hline
\end{tabular}




\begin{tabular}{|c|c|c|c|c|c|}
\hline \multirow{6}{*}{$S_{2}$} & \multirow{6}{*}{4.940} & \multirow{6}{*}{476.6} & \multirow{6}{*}{0.001} & $86->92$ & 0.16762 \\
\hline & & & & $88->93$ & -0.19085 \\
\hline & & & & $90->93$ & 0.18966 \\
\hline & & & & $90->95$ & -0.26658 \\
\hline & & & & $91->92$ & 0.26013 \\
\hline & & & & $91->94$ & 0.48633 \\
\hline
\end{tabular}

$\begin{array}{lll}\mathrm{V}_{\mathrm{ab}} & 0.057 & 5.5\end{array}$

Table S24. F2H2 open conformation at BLYP40/6-31G(d)

\begin{tabular}{|c|c|c|c|c|c|}
\hline & $E, e V$ & $\mathrm{E}, \mathrm{kJ} / \mathrm{mol}$ & $f$ & transition & coeff. \\
\hline \multirow{4}{*}{$\mathbf{S}_{1}$} & \multirow{4}{*}{4.857} & \multirow{4}{*}{468.6} & \multirow{4}{*}{0.1012} & $90->92$ & 0.36036 \\
\hline & & & & $90->93$ & 0.12218 \\
\hline & & & & 91 -> 92 & -0.34584 \\
\hline & & & & $91->93$ & 0.43929 \\
\hline \multirow{7}{*}{$S_{2}$} & \multirow{7}{*}{4.930} & \multirow{7}{*}{475.7} & \multirow{7}{*}{0.4861} & $86->92$ & -0.13227 \\
\hline & & & & $86->94$ & 0.10773 \\
\hline & & & & $90->92$ & 0.51468 \\
\hline & & & & $90->93$ & 0.14800 \\
\hline & & & & $90->94$ & 0.10537 \\
\hline & & & & $91->92$ & 0.18210 \\
\hline & & & & $91->93$ & -0.32144 \\
\hline $\mathbf{V}_{\mathrm{ab}}$ & 0.037 & 3.5 & & & \\
\hline
\end{tabular}

Table S25. F2H2 stacked conformation at BLYP40/6-31G(d)

\begin{tabular}{cccccc}
\hline & $\mathrm{E}, \mathrm{eV}$ & $\mathrm{E}, \mathrm{kJ} / \mathrm{mol}$ & $\boldsymbol{f}$ & transition & coeff. \\
\hline $\mathrm{S}_{\mathbf{1}}$ & 2.742 & 264.6 & 0.000 & $90->94$ & -0.12836 \\
\hline $\mathrm{S}_{\mathbf{2}}$ & 3.186 & \multirow{2}{*}{307.4} & 0.000 & $91->92$ & 0.6935 \\
\cline { 5 - 6 } & & & & $88->92$ & -0.18015 \\
\cline { 5 - 6 } & & & & $91->93$ & 0.67923 \\
\hline $\mathrm{V}_{\mathrm{ab}}$ & 0.222 & 21.4 & & & \\
\hline
\end{tabular}

Table S26. $(\mathrm{F})_{2}$ tilted orthogonal conformation at TD PBE0-GD3/def2-TZVP

\begin{tabular}{cccccc}
\hline & $\mathrm{E}, \mathrm{eV}$ & $\mathrm{E}, \mathrm{kJ} / \mathrm{mol}$ & $\boldsymbol{f}$ & transition & coeff. \\
\hline $\mathrm{S}_{1}$ & 3.320 & 320.4 & 0.0357 & $88->89$ & 0.70335 \\
\hline $\mathrm{S}_{\mathbf{2}}$ & 3.718 & 358.8 & 0.0654 & $87->89$ & -0.68184 \\
\cline { 5 - 6 } & & & & $88->90$ & 0.15911 \\
\hline $\mathrm{V}_{\mathrm{ab}}$ & 0.199 & 19.2 & & &
\end{tabular}

Table S27. $(\mathrm{F})_{2}$ tilted orthogonal conformation at TD PBE0-GD3/def-SV(P) 


\begin{tabular}{cccccc}
\hline & $\mathrm{E}, \mathrm{eV}$ & $\mathrm{E}, \mathrm{kJ} / \mathrm{mol}$ & $\boldsymbol{f}$ & transition & coeff. \\
\hline $\mathrm{S}_{1}$ & 3.173 & 306.2 & 0.0304 & $88->89$ & -0.70413 \\
\hline \multirow{2}{*}{$\mathrm{S}_{2}$} & 3.661 & 353.2 & 0.056 & $87->89$ & 0.67832 \\
\cline { 5 - 6 } & & & & $88->90$ & -0.17576 \\
\hline $\mathrm{V}_{\mathrm{ab}}$ & 0.244 & 23.5 & & & \\
\hline
\end{tabular}

Table S28. $(\mathrm{F})_{2}$ tilted orthogonal conformation at BLYP40/6-31G(d)

\begin{tabular}{cccccc} 
& $\mathrm{E}, \mathrm{eV}$ & $\mathrm{E}, \mathrm{kJ} / \mathrm{mol}$ & $\boldsymbol{f}$ & transition & coeff. \\
\hline $\mathrm{S}_{1}$ & 4.083 & 394.0 & 0.1738 & $88->89$ & 0.69557 \\
\hline $\mathrm{S}_{\mathbf{2}}$ & 4.393 & 423.9 & 0.1069 & $87->89$ & -0.68628 \\
\hline $\mathrm{V}_{\mathrm{ab}}$ & 0.155 & 14.9 & & & \\
\hline
\end{tabular}

Table S29. $(\mathrm{F})_{2}$ sandwich conformation at TD PBE0-GD3/def2-TZVP

\begin{tabular}{cccccc}
\hline & $\mathrm{E}, \mathrm{eV}$ & $\mathrm{E}, \mathrm{kJ} / \mathrm{mol}$ & $\boldsymbol{f}$ & transition & coeff. \\
\hline $\mathrm{S}_{1}$ & 3.145 & 303.5 & 0.0000 & $88->89$ & -0.70494 \\
\hline & & & & $85->89$ & 0.18232 \\
\cline { 5 - 6 } $\mathrm{S}_{2}$ & 3.865 & 372.9 & 0.0213 & $88->90$ & 0.61715 \\
\cline { 5 - 6 } & & & & $88->91$ & 0.26988 \\
\hline $\mathrm{V}_{\mathrm{ab}}$ & 0.360 & 34.7 & & & \\
\end{tabular}

Table S30. $(\mathrm{F})_{2}$ TD sandwich conformation at PBE0-GD3/def2-SV(P)

\begin{tabular}{cccccc}
\hline & $\mathrm{E}, \mathrm{eV}$ & $\mathrm{E}, \mathrm{kJ} / \mathrm{mol}$ & $\boldsymbol{f}$ & transition & coeff. \\
\hline $\mathrm{S}_{1}$ & 3.130 & 302.0 & 0.0000 & $88->89$ & 0.70509 \\
\hline & & & & $85>89$ & -0.18865 \\
\cline { 5 - 6 } $\mathrm{S}_{2}$ & 3.860 & 372.5 & 0.0328 & $88>90$ & 0.63599 \\
\cline { 5 - 6 } & & & & $88>91$ & 0.22034 \\
\hline $\mathrm{V}_{\mathrm{ab}}$ & 0.365 & 35.3 & & & \\
\hline
\end{tabular}

Table S31. $(\mathrm{F})_{2}$ sandwich conformation at BLYP40/6-31G(d)

\begin{tabular}{cccccc} 
& $\mathrm{E}, \mathrm{eV}$ & $\mathrm{E}, \mathrm{kJ} / \mathrm{mol}$ & $\boldsymbol{f}$ & transition & coeff. \\
\hline $\mathrm{S}_{1}$ & 3.652 & 352.3 & 0.0000 & $88>89$ & 0.70121 \\
\hline & & & & $85>89$ & -0.17886 \\
\cline { 5 - 6 } $\mathrm{S}_{2}$ & 4.330 & 417.8 & 0.0548 & $88>90$ & 0.60182 \\
\cline { 5 - 6 } & & & & $88>91$ & 0.29136 \\
\hline $\mathrm{V}_{\mathrm{ab}}$ & 0.339 & 32.7 & & & \\
\hline
\end{tabular}


Table S32. $(\mathrm{F})_{2}$ parallel displaced S1 conformation at TD PBE0-GD3/def2-TZVP

\begin{tabular}{cccccc} 
& $\mathrm{E}, \mathrm{eV}$ & $\mathrm{E}, \mathrm{kJ} / \mathrm{mol}$ & $\boldsymbol{f}$ & transition & coeff. \\
\hline $\mathrm{S}_{1}$ & 3.652 & 352.3 & 0.0000 & $88->89$ & 0.70121 \\
\hline & & & & $85>89$ & -0.17886 \\
$\mathrm{~S}_{2}$ & 4.330 & 417.8 & 0.0548 & $88>90$ & 0.60182 \\
\cline { 5 - 6 } & & & & $88>91$ & 0.29136 \\
\hline $\mathrm{V}_{\mathrm{ab}}$ & 0.302 & 29.2 & & & \\
\hline
\end{tabular}

Table S33. $(\mathrm{F})_{2}$ parallel displaced S1 conformation at TD PBE0-GD3/def2-SV(P)

\begin{tabular}{cccccc} 
& $\mathrm{E}, \mathrm{eV}$ & $\mathrm{E}, \mathrm{kJ} / \mathrm{mol}$ & $\boldsymbol{f}$ & transition & coeff. \\
\hline $\mathrm{S}_{\mathbf{1}}$ & 3.430 & 331.0 & 0.0000 & $88->89$ & 0.70322 \\
\hline $\mathrm{S}_{\mathbf{2}}$ & 4.085 & 394.1 & 0.0018 & $87->89$ & -0.4989 \\
\cline { 5 - 6 } & & & & $88->90$ & 0.48149 \\
\hline $\mathrm{V}_{\mathrm{ab}}$ & 0.327 & 31.6 & & &
\end{tabular}

Table S34. $(\mathrm{F})_{2}$ parallel displaced S1 conformation at BLYP40/6-31G(d)

\begin{tabular}{cccccc} 
& $\mathrm{E}, \mathrm{eV}$ & $\mathrm{E}, \mathrm{kJ} / \mathrm{mol}$ & $\boldsymbol{f}$ & transition & coeff. \\
\hline $\mathrm{S}_{1}$ & 3.978 & 383.8 & 0.0000 & $88->89$ & 0.69431 \\
\hline & & & & $87->89$ & -0.57423 \\
\cline { 5 - 6 } $\mathrm{S}_{2}$ & 4.634 & 447.1 & 0.7097 & $88->90$ & 0.36056 \\
\cline { 5 - 6 } & & & & $88->91$ & 0.10227 \\
\hline $\mathrm{V}_{\mathrm{ab}}$ & 0.328 & 31.7 & & & \\
\hline
\end{tabular}

Table S35. $(\mathrm{F})_{2}$ parallel displaced S0 at TD PBE0-GD3/def2-TZVP

\begin{tabular}{cccccc} 
& $\mathrm{E}, \mathrm{eV}$ & $\mathrm{E}, \mathrm{kJ} / \mathrm{mol}$ & $\mathbf{f}$ & transition & coeff. \\
\hline $\mathrm{S}_{1}$ & 4.333 & 418.1 & 0.0000 & $88->89$ & 0.68598 \\
\hline & & & & $87-89$ & 0.63532 \\
\cline { 5 - 6 } $\mathrm{S}_{2}$ & 4.592 & 443.1 & 0.2092 & $87->91$ & -0.14154 \\
\cline { 5 - 6 } & & & & $88->90$ & -0.11391 \\
\cline { 5 - 6 } & & & & $88->92$ & -0.17842 \\
\hline $\mathrm{V}_{\mathrm{ab}}$ & 0.129 & 12.5 & & & \\
\hline
\end{tabular}

Table S36. $(\mathrm{F})_{2}$ parallel displaced S0 at TD PBE0-GD3/def2-SV(P)

\begin{tabular}{cccccc} 
& $\mathrm{E}, \mathrm{eV}$ & $\mathrm{E}, \mathrm{kJ} / \mathrm{mol}$ & $\mathbf{f}$ & transition & coeff. \\
\hline $\mathrm{S}_{1}$ & 4.358 & 420.5 & 0.0000 & $88->89$ & 0.69044 \\
\hline $\mathrm{S}_{2}$ & 4.631 & 446.9 & 0.1153 & $87->89$ & 0.6209 \\
\cline { 5 - 6 } & & & & $88->90$ & -0.29672 \\
\hline $\mathrm{V}_{\mathrm{ab}}$ & 0.137 & 13.2 & & & \\
\hline
\end{tabular}


Table S37. (F) 2 parallel displaced S0 at BLYP40/6-31G(d)

\begin{tabular}{|c|c|c|c|c|c|}
\hline & $E, \mathrm{eV}$ & $\mathrm{E}, \mathrm{kJ} / \mathrm{mol}$ & $f$ & transition & coeff. \\
\hline \multirow{2}{*}{$S_{1}$} & \multirow{2}{*}{4.867} & \multirow{2}{*}{469.6} & \multirow{2}{*}{0.0000} & $87->90$ & 0.32979 \\
\hline & & & & $88->89$ & 0.57413 \\
\hline \multirow{7}{*}{$S_{2}$} & \multirow{7}{*}{4.968} & \multirow{7}{*}{479.3} & \multirow{7}{*}{0.5755} & $83->90$ & -0.11755 \\
\hline & & & & $84->89$ & -0.12246 \\
\hline & & & & $84->91$ & 0.1038 \\
\hline & & & & $87->89$ & 0.44965 \\
\hline & & & & $87->91$ & 0.14914 \\
\hline & & & & $88->90$ & 0.42248 \\
\hline & & & & $88->92$ & -0.15043 \\
\hline$V_{a b}$ & 0.050 & 4.9 & & & \\
\hline
\end{tabular}

Table S38. $(\mathrm{F})_{2}$ parallel orthogonal at TD PBE0-GD3/def2-TZVP

\begin{tabular}{|c|c|c|c|c|c|}
\hline & $E, e V$ & $\mathrm{E}, \mathrm{kJ} / \mathrm{mol}$ & $f$ & transition & coeff. \\
\hline \multirow[t]{4}{*}{ S1 } & 4.451 & 429.4 & 0.0622 & $87->90$ & -0.11811 \\
\hline & & & & 87 -> 92 & 0.10413 \\
\hline & & & & 88 -> 89 & 0.66232 \\
\hline & & & & 88 -> 91 & -0.11351 \\
\hline \multirow[t]{3}{*}{ S2 } & 4.466 & 430.9 & 0.0662 & 87 -> 89 & 0.65419 \\
\hline & & & & 87 -> 91 & -0.10521 \\
\hline & & & & 88 -> 90 & -0.16696 \\
\hline
\end{tabular}

$\begin{array}{lll}\text { Vab } & 0.008 & 0.8\end{array}$

Table S39. $(\mathrm{F})_{2}$ parallel orthogonal at TD PBE0-GD3/def2-SV(P)

\begin{tabular}{cccccc}
\hline & $\mathrm{E}, \mathrm{eV}$ & $\mathrm{E}, \mathrm{kJ} / \mathrm{mol}$ & $\mathbf{f}$ & transition & coeff. \\
\hline S1 & 4.501 & 434.3 & 0.0494 & $87->90$ & 0.1927 \\
\cline { 5 - 6 } & & & & $88->89$ & 0.65135 \\
\hline S2 & 4.515 & 435.6 & 0.0444 & $87->89$ & 0.63633 \\
\cline { 5 - 6 } & & & & $88->90$ & 0.24853 \\
\hline Vab & 0.007 & 0.7 & & &
\end{tabular}

$\begin{array}{lll}\text { Vab } & 0.007 & 0.7\end{array}$ 
Table S40. $(\mathrm{F})_{2}$ parallel orthogonal at BLYP40/6-31G(d)

\begin{tabular}{|c|c|c|c|c|c|}
\hline & $E, e V$ & $\mathrm{E}, \mathrm{kJ} / \mathrm{mol}$ & f & transition & coeff. \\
\hline \multirow[t]{4}{*}{ S1 } & 4.891 & 471.9 & 0.2302 & $84->89$ & 0.10817 \\
\hline & & & & 87 -> 90 & -0.28858 \\
\hline & & & & 87 -> 92 & 0.10686 \\
\hline & & & & 88 -> 89 & 0.59097 \\
\hline \multirow[t]{3}{*}{ S2 } & 4.897 & 472.5 & 0.257 & 87 -> 89 & 0.59209 \\
\hline & & & & 88 -> 90 & -0.2771 \\
\hline & & & & $88->92$ & 0.11635 \\
\hline Vab & 0.003 & 0.3 & & & \\
\hline
\end{tabular}




\section{References}

(1) Dietz, T. G.; Duncan, M. A.; Liverman, M. G.; Smalley, R. E. J Chem Phys 1980, 73, 4816.

(2) Frisch, M. J.; Trucks, G. W.; Schlegel, H. B.; Scuseria, G. E.; Robb, M. A.; Cheeseman, J. R.; Scalmani, G.; Barone, V.; Mennucci, B.; Petersson, G. A.; Nakatsuji, H.; Caricato, M.; Li, X.; Hratchian, H. P.; Izmaylov, A. F.; Bloino, J.; Zheng, G.; Sonnenberg, J. L.; Hada, M.; Ehara, M.; Toyota, K.; Fukuda, R.; Hasegawa, J.; Ishida, M.; Nakajima, T.; Honda, Y.; Kitao, O.; Nakai, H.; Vreven, T.; Montgomery, J., J. A.; Peralta, J. E.; Ogliaro, F.; Bearpark, M.; Heyd, J. J.; Brothers, E.; Kudin, K. N.; Staroverov, V. N.; Keith, T.; Kobayashi, R.; Normand, J.; Raghavachari, K.; Rendell, A.; Burant, J. C.; Iyengar, S. S.; Tomasi, J.; Cossi, M.; Rega, N.; Millam, J. M.; Klene, M.; Knox, J. E.; Cross, J. B.; Bakken, V.; Adamo, C.; Jaramillo, J.; Gomperts, R.; Stratmann, R. E.; Yazyev, O.; Austin, A. J.; Cammi, R.; Pomelli, C.; Ochterski, J. W.; Martin, R. L.; Morokuma, K.; Zakrzewski, V. G.; Voth, G. A.; Salvador, P.; Dannenberg, J. J.; Dapprich, S.; Daniels, A. D.; Farkas, O.; Foresman, J. B.; Ortiz, J. V.; Cioslowski, J.; Fox, D. J. In Gaussian 09, Revision D.01; Gaussian, Inc., Wallingford CT: 2010.

(3) Sinnokrot, M. O.; Sherrill, C. D. J Phys Chem A 2004, 108, 10200.

(4) Perdew, J. P.; Ernzerhof, M.; Burke, K. J Chem Phys 1996, 105, 9982.

(5) Adamo, C.; Barone, V. J Chem Phys. 1999, 110, 6158.

(6) Grimme, S.; Antony, J.; Ehrlich, S.; Krieg, H. J Chem Phys 2010, 132, 154104.

(7) Wang, W.; Sun, T.; Zhang, Y.; Wang, Y.-B. J Chem Phys 2015, 143, 114312.

(8) Weigend, F. Phys Chem Chem Phys 2006, 8, 1057.

(9) Weigend, F.; Ahlrichs, R. Phys Chem Chem Phys 2005, 7, 3297.

(10) Casida, M. E.; Jamorski, C.; Casida, K. C.; Salahub, D. R. J Chem Phys 1998, 108, 4439 .

(11) Stratmann, R. E.; Scuseria, G. E.; Frisch, M. J. J Chem Phys 1998, 109, 8218.

(12) Talipov, M. R.; Boddeda, A.; Timerghazin, Q. K.; Rathore, R. J Phys Chem C 2014, 118, 21400.

(13) Renz, M.; Kess, M.; Diedenhofen, M.; Klamt, A.; Kaupp, M. J Chem Theory Comput 2012, 8, 4189.

(14) Renz, M.; Theilacker, K.; Lambert, C.; Kaupp, M. J Am Chem Soc 2009, $131,16292$.

(15) Adamo, C.; Barone, V. Chem Phys Lett 1997, 274, 242.

(16) Hehre, W. J.; Ditchfield, R.; Pople, J. A. J Chem Phys 1972, 56, 2257.

(17) Bauernschmitt, R.; Ahlrichs, R. J Chem Phys 1996, 104, 9047.

(18) Seeger, R.; Pople, J. A. J Chem Phys 1977, 66, 3045.

(19) Jónsson, H.; Mills, G.; Jacobsen, K. W. 1998.

(20) Kästner, J.; Carr, J. M.; Keal, T. W.; Thiel, W.; Wander, A.; Sherwood, P. $J$ Phys Chem A 2009, 113, 11856.

(21) Ivanova, L. V.; Anton, B. J.; Timerghazin, Q. K. Phys Chem Chem Phys 2014, $16,8476$. 